\title{
Decadal Modulation of Transbasin Variability on Extended Boreal Summer Tropical Cyclone Activity in the Tropical North Pacific and Atlantic Basins
}

\author{
Shaohua Chen, ${ }^{\mathrm{a}, \mathrm{b}, \mathrm{c}}$ Haikun ZhaO,${ }^{\mathrm{a}, \mathrm{b}, \mathrm{c}}$ Philp J. Klotzbach, ${ }^{\mathrm{d}}$ Graciela B. Raga, ${ }^{\mathrm{e}}$ Jian CaO, ${ }^{\mathrm{a}, \mathrm{c}}$ AND \\ CHAO WANG ${ }^{\text {a,c }}$ \\ ${ }^{a}$ Key Laboratory of Meteorological Disaster, Ministry of Education, Pacific Typhoon Research Center, Nanjing University of \\ Information Science and Technology, Nanjing, China \\ ${ }^{\mathrm{b}}$ State Key Laboratory of Severe Weather, Chinese Academy of Meteorological Sciences, Beijing, China \\ ${ }^{\mathrm{c}}$ Joint International Research Laboratory of Climate and Environment Change, and Collaborative Innovation Center on Forecast \\ and Evaluation of Meteorological Disaster, Nanjing University of Information Science and Technology, Nanjing, China \\ ${ }^{\mathrm{d}}$ Department of Atmospheric Science, Colorado State University, Fort Collins, Colorado \\ ${ }^{\text {e } C e n t r o ~ d e ~ C i e n c i a s ~ d e ~ l a ~ A t m o ́ s f e r a, ~ U n i v e r s i d a d ~ N a c i o n a l ~ A u t o ́ n o m a ~ d e ~ M e x i c o, ~ M e x i c o ~ C i t y, ~ M e x i c o ~}$
}

(Manuscript received 8 April 2020, in final form 3 June 2021)

\begin{abstract}
This study analyzes decadal modulation of transbasin variability (TBV) on extended boreal summer (MayOctober) tropical cyclone frequency (TCF) over the western North Pacific (WNP), central-eastern North Pacific (CENP), and North Atlantic (NATL) basins. There are distinct decadal regimes (P1: 1979-97, P2: 1998-2008, and P3: 2009-19) with changes in the interannual relationship between TBV and TCF over these three basins. During P1 and P3, there is a significant interannual TBV-TCF relationship over the CENP and NATL, but these relationships become insignificant during P2. Changes in the interannual TBV-TCF relationship over the WNP are opposite to those over the CENP and NATL basins, with significant relationship during $\mathrm{P} 2$ but insignificant relationship during $\mathrm{P} 1$ and $\mathrm{P} 3$. Changes in all three basins coincide with decadal changes in large-scale parameters associated with TBV. Consistent basinwide changes in lower-tropospheric vorticity (vertical wind shear) associated with TBV appear to be largely responsible for changes in total TCF over the NATL (CENP) during P1 and P3. In contrast, a dipole pattern in lower-tropospheric vorticity and vertical wind shear anomalies associated with TBV over the NATL and CENP basins occurs during P2, leading to an insignificant interannual TBV-TCF relationship over the NATL and CENP basins. Over the WNP, a basinwide consistent distribution of lower-tropospheric vorticity associated with TBV is consistent with changes in total TCF during P2, whereas a dipole correlation pattern between TBV-associated factors and TCF during P1 and P3 leads to a weak correlation between TBV and WNP TCF. These three distinct observed decadal regimes may be associated with interactions between ENSO and the Pacific decadal oscillation on decadal time scales.
\end{abstract}

KEYWORDS: Tropical cyclones; Climate variability; Decadal variability; Interannual variability; Pacific decadal oscillation

\section{Introduction}

Tropical cyclones (TCs) are one of the most destructive natural disasters in the world, often leading to loss of life and property in coastal regions (Zhang et al. 2009, 2011; Klotzbach et al. 2018). The western North Pacific (WNP) (west of the International Date Line), central-eastern North Pacific (CENP) (east of the International Date Line), and North Atlantic (NATL) basins are three of the most active regions for TC genesis, respectively accounting for $\sim 33 \%, \sim 20 \%$, and $\sim 15 \%$ of the global total number of TCs, based on a 1981-2010 climatology (Schreck et al. 2014). Over the past several decades, remarkable progress has been made in both operational forecasting as well as the physical understanding of TC tracks (Wu and Wang 2004; Camargo et al. 2007; Liu and Chan 2008; Ho et al. 2009; Zhao et al. 2010; Hong et al. 2011; Zhao and Wu 2014). Nevertheless, the associated physical mechanisms underlying TC genesis and TC intensity evolution remain somewhat incomplete (Gray 1975; Craig and Gray 1996; Rogers et al. 2006; Montgomery et al. 2012). Recent studies have suggested that global warming may reduce TC genesis frequency given both increased vertical wind shear

Corresponding author: Haikun Zhao, zhk2004y@gmail.com and enhanced static stability (Yoshimura et al. 2006; Oouchi et al. 2006; Sugi et al. 2009, 2012; Murakami et al. 2011; Knutson et al. 2010; Held and Zhao 2011), while other studies have suggested an increase in TCs in response to global warming (Haarsma et al. 1993; Royer et al. 1998; Emanuel 2013). To enhance understanding of the possible impact of global warming on TC genesis frequency, it is important to explore the associated physical mechanisms impacting TC genesis on both global as well as basinwide scales and various climate time scales.

On interannual time scales, changes in sea surface temperature anomalies (SSTAs) over various basins have been demonstrated to exert an apparent impact on both oceanic and atmospheric large-scale conditions and thus, on TC genesis frequency (Wang and Chan 2002; Xie et al. 2009; Du et al. 2011; Zhan et al. 2011; Ha et al. 2015). For example, it has been widely recognized that ENSO is a dominant factor in modulating annual TC frequency (TCF) through alterations in both the thermodynamic and dynamic environment (Rasmusson and Carpenter 1982; Chan 1985; Lander 1994; Wang and Chan 2002; Camargo and Sobel 2005; Patricola et al. 2018). Over the WNP basin, more TCs occur over the southeastern WNP during El Niño years compared with La Niña years, primarily due to the extension of the monsoon trough and associated changes in large-scale factors and synoptic-scale 
wave activity (Chan 1985; Lander 1994; Sobel and Maloney 2000; Wang and Chan 2002; Camargo and Sobel 2005). ENSOassociated SSTs and vertical wind shear (VWS) are two important factors modulating TCF over the western portion of the CENP basin (Camargo et al. 2007; Collins 2007; Klotzbach and Blake 2013; Jien et al. 2015). Over the NATL basin, enhanced (weakened) upper-level westerlies and increased (decreased) vertical wind shear (VWS) during El Niño (La Niña) events generally cause fewer (more) TCs (Gray 1984; Goldenberg and Shapiro 1996; Iizuka and Matsuura 2009; Klotzbach 2011). In addition to ENSO, tropical Indian Ocean (TIO) SSTAs also exert a significant impact on WNP TCs by inducing warming Kelvin waves that also change Indo-Pacific summer climate patterns (Xie et al. 2009; Du et al. 2011; Zhan et al. 2011; Ha et al. 2015). Recent studies have suggested that tropical NATL SSTAs have a significant interannual association with WNP TC frequency (Huo et al. 2015; Yu et al. 2016; Gao et al. 2018). Wang and Lee (2009) suggested a covariability of tropical cyclones in the NATL and CENP basins on both interannual and multidecadal timescales. Their analyses showed that both vertical wind shear and convective instability associated with Pacific and Atlantic SSTs contributed to the out-of-phase relationship between these two basins. Additionally, Caron et al. (2015) also found that SSTs in the NATL subpolar gyre were an important predictor in forecasting CENP TC frequency. In summary, the direct and remote impacts of changes in SSTAs over various ocean basins on TCs have been well documented in prior studies. However, current studies have mainly focused on the respective impacts of changes in specific basin SSTAs, but the impact of the combined effect of changes in SSTs in different tropical ocean basins on TCs in these basins remains somewhat unclear.

There has recently been growing interest in interbasin interactions and their impacts, particularly among the tropical Pacific-Indian-Atlantic sector (McGregor et al. 2014; Chikamoto et al. 2015; Yang et al. 2017; Luo et al. 2017; Cai et al. 2019), with a focus on transbasin variability (TBV). TBV is characterized by a seesaw relationship generally found between SST and SLP in the Pacific Ocean and the Atlantic and Indian Oceans. As noted in previous studies on TBV, there is a relatively quickly varying Pacific SST/sea level pressure (SLP) signal and a more slowly varying SST/SLP signal over the Atlantic and Indian Oceans (McGregor et al. 2014; Choudhury et al. 2017). These changes can be distinguished on interannual and interdecadal time scales from ENSO. Correspondingly, we expect that the impact of large-scale factors associated with TBV on TC activity would be distinguishable from the impact of ENSO. On decadal time scales, for example, Pacific trade winds have been demonstrated to be substantially influenced by TBV, primarily due to associated changes in the SST gradient between the western and eastern Pacific (McGregor et al. 2014, 2018).

Recent studies have suggested that there are interdecadal and decadal changes in the association of WNP TCs with ENSO (Zhao and Wang 2016, 2019; Wang and Liu 2016; Hu et al. 2018; Zhao et al. 2019a), with TIO SSTAs (Zhan et al. 2014), and with tropical NATL SSTAs (Cao et al. 2016; Chang et al. 2016). These may be associated with both the Pacific climate regime shift as well as shifting ENSO conditions (Xiang et al. 2013; Hu et al. 2018; Zhao and Wang 2019; Zhao et al. 2019a). Yoon and Yeh (2010) found that the relationship between ENSO and the northeast Asian monsoon as well as precipitation intensified when the Pacific decadal oscillation (PDO) and ENSO were in phase and weakened when the PDO and ENSO were out of phase. A similar response to the PDO is observed for both total TCF and rapidly intensifying TCF and ENSO in the WNP, accompanied by an enhanced (weakened) relationship in the cold (warm) PDO phase (Zhao et al. 2019a; Zhao and Wang 2019; Wang and Liu 2016). Moreover, there has been an increased association between WNP TCF and tropical NATL SSTs since the 1990s (Cao et al. 2016; Chang et al. 2016), as well as a stronger relationship between WNP TCF and TIO SSTAs since the 1970s (Zhan et al. 2014). These previous results lead to the following questions:

Does the interannual relationship between TBV and TCF over the WNP, CENP, and NATL basins experience decadal changes?

If yes, what are the associated physical mechanisms on decadal time scales that dictate the changes in their interannual relationships?

These are the research questions considered in this study, which is organized as follows. Section 2 describes the datasets and methodology. Section 3 documents decadal changes in the interannual relationship between TBV and TCF over the WNP, CENP, and NATL basins. Modulations of the TBV-associated large-scale environmental factors affecting TCF over the WNP, CENP, and NATL basins are investigated in section 4. Section 5 explores a potential physical mechanism causing the decadal modulation of the interannual TBV-TCF relationship. Section 6 provides a discussion and is followed by a brief summary in section 7 .

\section{Data and methodology}

The TC best track datasets over the WNP, CENP, and NATL basins during 1979-2019 are obtained from the International Best Track Archive for Climate Stewardship (IBTrACS) version 4 (Knapp et al. 2010). This dataset includes longitude, latitude, maximum sustained surface wind speed, and minimum central sea level pressure at a 6-h interval. We use data from the U.S. National Hurricane Center (NHC) and Joint Typhoon Warning Center (JTWC) as archived in IBTrACS to provide the coverage for our study region. NHC data cover the NATL and CENP basins (e.g., HURDAT2; Landsea and Franklin 2013). The TC data for the WNP are from the JTWC (Chu et al. 2002). To reduce uncertainties due to the different TC best track agencies in the WNP (Song and Klotzbach 2018), a system is classified as a TC when its maximum sustained surface wind is greater than or equal to $34 \mathrm{kt}$ $\left(\sim 17 \mathrm{~m} \mathrm{~s}^{-1}\right)$ and simultaneously recorded by all four source best track agencies in the WNP (e.g., the JTWC, Japan Meteorological Agency, China Meteorological Administration, and Hong Kong Observatory). The TC frequency is counted as the total number of TC formations. The TC formation location is recorded as the location where the TC first attains 34-kt intensity.

Monthly mean SST data are taken from the National Oceanic and Atmospheric Administration's (NOAA) Extended Reconstructed Sea Surface Temperature (ERSST) version 4 (ERSST v4) with a horizontal resolution of $2.0^{\circ} \times 2.0^{\circ}$ (Huang et al. 2015; Liu et al. 2015). Monthly mean atmospheric fields are obtained from the National Centers for Environmental Prediction-Department 
(a) Cor.TBV-SST(Shading)/SLP(Contour)

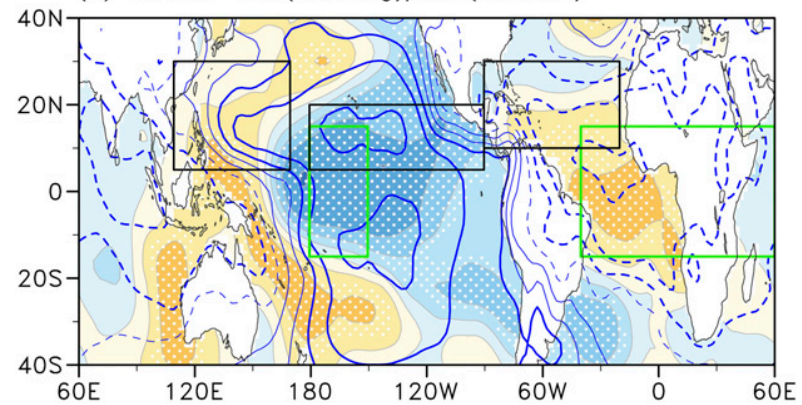

(b) Cor.TBV-VWS

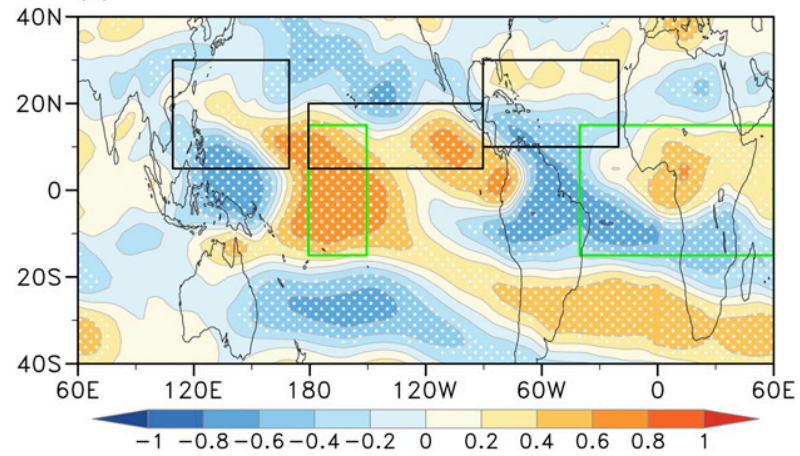

FIG. 1. (a) Correlation between the TBV index and borealsummer-averaged SST (shading) and sea level pressure (SLP) (contours). (b) As in (a), but for correlations between TBV and vertical wind shear (VWS). The $95 \%$ significance level is indicated with white dots for shaded fields and bold contours for contoured fields. The black and green boxes are the subregions for the analyses and the regions that are used to define the TBV index, respectively.

of Energy (NCEP-DOE) AMIP-II reanalysis dataset with a horizontal resolution of $2.5^{\circ} \times 2.5^{\circ}$ and 17 vertical pressure levels (Kanamitsu et al. 2002). Vertical wind shear is calculated as the magnitude of the vector wind difference between winds at 850 and $200 \mathrm{hPa}$. The TBV index, following Chikamoto et al. (2015), is defined in this study as the zonal difference between standardized SLP anomalies between the tropical central Pacific $\left(15^{\circ} \mathrm{S}-15^{\circ} \mathrm{N}\right.$, $\left.180^{\circ}-150^{\circ} \mathrm{W}\right)$ and the tropical Atlantic and Indian Oceans $\left(15^{\circ} \mathrm{S}-\right.$ $\left.15^{\circ} \mathrm{N}, 40^{\circ}-60^{\circ} \mathrm{E}\right)$. In this manuscript, we define the main development regions where most TCs ( $>90 \%$ of the total TCs) form in each basin. The latitude/longitude boundaries of these main development regions for the $\mathrm{WNP}$ are $5^{\circ}-30^{\circ} \mathrm{N}, 110^{\circ}-170^{\circ} \mathrm{E}$, for the CENP are $5^{\circ}-$ $20^{\circ} \mathrm{N}, 180^{\circ}-90^{\circ} \mathrm{W}$, and for the NATL are $10^{\circ}-30^{\circ} \mathrm{N}, 90^{\circ}-20^{\circ} \mathrm{W}$.

The significance of correlation coefficients between TBV and TC counts as well as large-scale environmental variables are obtained using a two-tailed Student's $t$ test. Correlations are considered significant at the 5\% confidence level using a threshold of 0.31 for the whole period of 1979-2019, 0.45 during 197997, 0.60 during 1998-2008, and 0.60 during 2009-19, respectively.

\section{Decadal change in the interannual relationship between TBV and TC frequency}

Figure 1a shows the observed correlations between global SST and SLP and the TBV index during the period from 1979

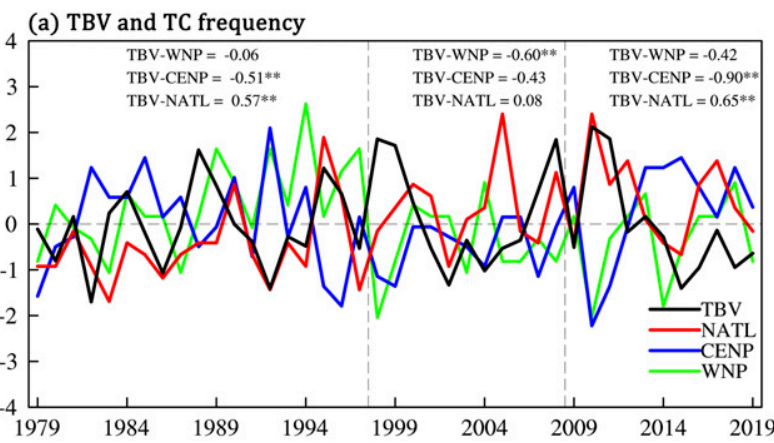

(b) Nino-3.4 and TC frequency

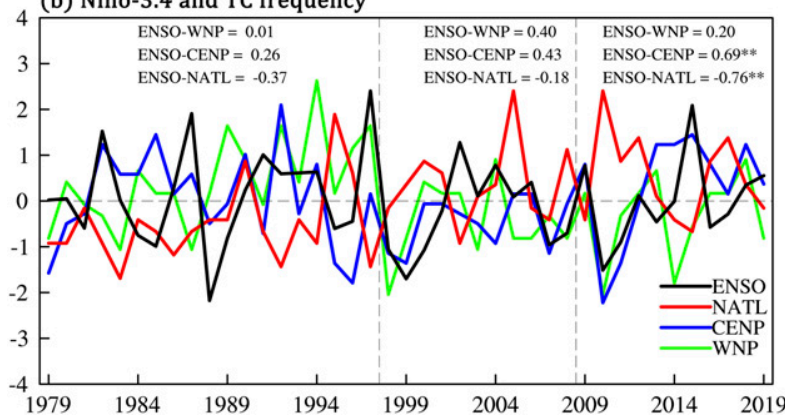

FIG. 2. (a) Normalized time series of the transbasin variability (TBV) index and TC frequency (TCF) over the whole tropical WNP, CENP, and NATL basins $\left(0^{\circ}-30^{\circ} \mathrm{N}\right)$ during the extended boreal summer (May-October) from 1979 to 2019. The correlation coefficients between TBV and TC counts in each basin during 1979-97, 1998-2008, 2009-19 are also shown. (b) As in (a), but for the Nino-3.4 index and TCF. The values with two asterisks $(* *)$ are significant at the $95 \%$ confidence level.

to 2019, with the noted seesaw relationship between the centraleastern Pacific and the Atlantic/Indian Oceans. This observed TBV structure may be related to the covariability of the Indian Ocean dipole and ENSO (Choudhury et al. 2017). Other largescale parameters show significant correlations with the TBV. As shown in Fig. 1b, the correlation map displaying the TBV-VWS relationship exhibits a meridional dipole distribution over the WNP basin, a consistent basinwide positive correlation over the CENP basin, and a consistent basinwide negative correlation over the NATL basin.

TBV's modulation of TCF over the WNP, CENP, and NATL basins has pronounced decadal changes, as shown in Fig. 2a, with three distinctly identifiable decadal regimes: P1 (1979-97), P2 (1998-2008), and P3 (2009-19). The total TCF over the WNP basin has a significant correlation $(r=-0.60)$ with TBV during $\mathrm{P} 2$, while this significant association becomes insignificant during both $\mathrm{P} 1(r=-0.06)$ and P3 $(r=-0.42)$. By contrast, TC counts over the CENP and NATL basins both have significant correlations with TBV during P1 and P3 (CENP: $r=-0.51$ and $r=-0.90$; NATL: $r=0.57$ and $r=0.65$ ), respectively, but their correlations become insignificant during $\mathrm{P} 2$, with an especially weak correlation over the NATL basin (CENP: $r=-0.43$; NATL: $r=0.08$ ). These decadal changes in the TBV-TCF correlation are further confirmed using a Fisher's test through $Z$ transformation (Fisher 1915), with 

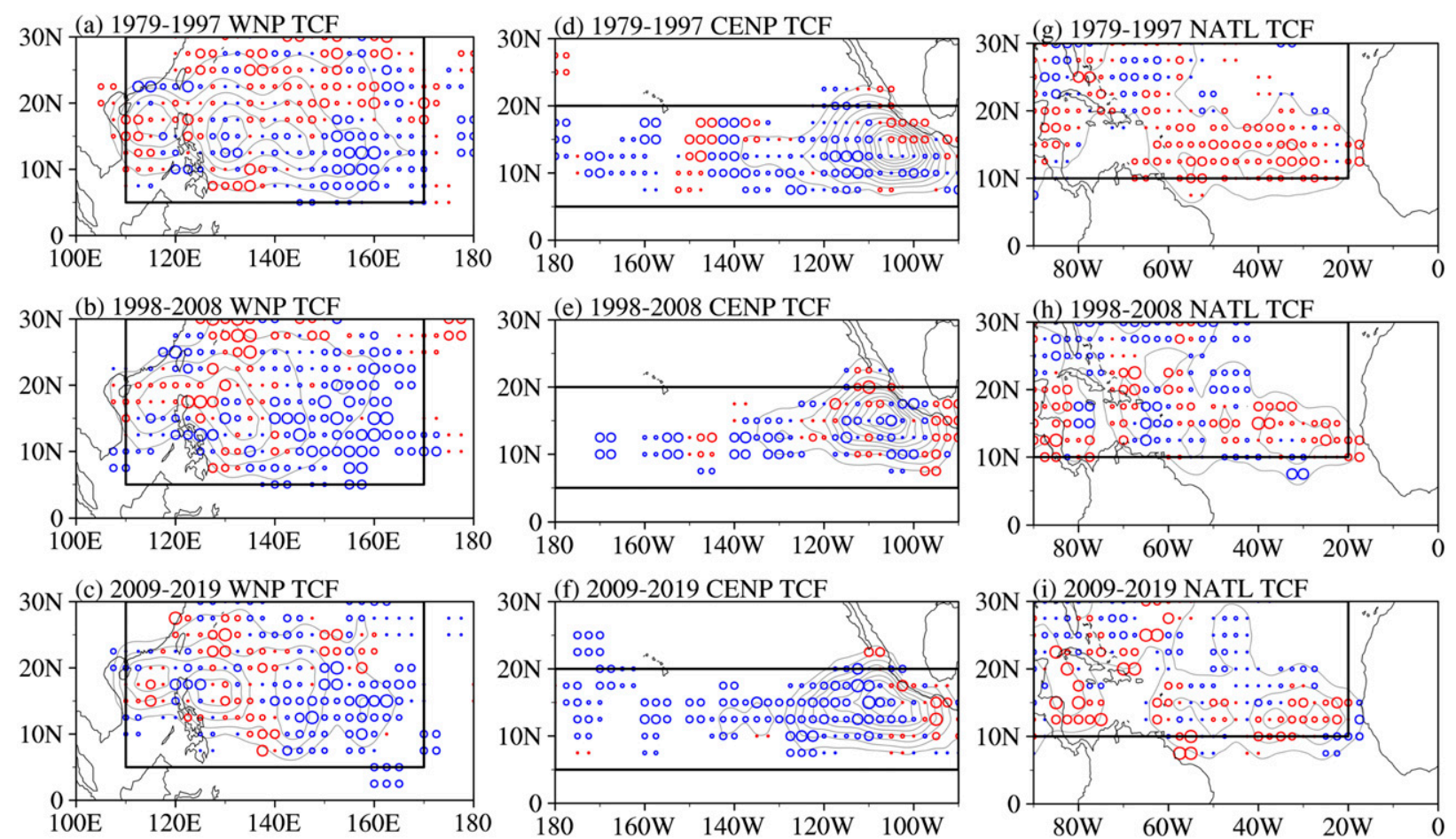

$$
\begin{array}{ccccccccc}
\cdot 0 \sim+0.1 & \cdot+0.1 \sim+0.2 & \circ & +0.2 \sim+0.3 & \circ & +0.3 \sim+0.4 & \circ & +0.4 \sim+0.5 \\
\cdot-0.1 \sim 0 & \circ-0.2 \sim-0.1 & \circ & -0.3 \sim-0.2 & \circ & -0.4 \sim-0.3 & \circ & -0.5 \sim-0.4
\end{array}
$$

$$
\begin{array}{llll}
\circ+0.5 \sim+0.6 & \circ & +0.6 \sim+0.7 \\
\circ & -0.6 \sim-0.5 & \circ & -0.7 \sim-0.6
\end{array}
$$

FIG. 3. Climatological TCF (contours) over the (a)-(c) WNP, (d)-(f) CENP, and (g)-(i) NATL basins during (top) P1, (middle) P2, and (bottom) P3. Marks indicate the correlation pattern between TCF and the TBV index with red (blue) markers denoting positive (negative) values. The sizes of the markers highlight the magnitude of the correlation. The black boxes give the subregions chosen as the main development regions.

pronounced decadal changes in the correlation strength from $\mathrm{P} 1$ to P2 in the WNP and NATL basins and from P2 to P3 in the CENP and NATL basins (figure not shown). We also compute correlations between the Niño-3.4 index and total TCF over these three basins, but there is no evidence of three distinct regimes in their interannual relationship (Fig. 2b), suggesting that TBV significantly modulates TCs apart from TBV's relationship with ENSO.

We next examine decadal changes in the modulation of TBV on TCF over these three basins via their spatial correlation patterns (Fig. 3). Over the WNP basin, an apparent dipole of TCs associated with TBV is found during $\mathrm{P} 1$ and $\mathrm{P} 3$, respectively, with a southnorth dipole pattern during P1 and a southeast-northwest dipole pattern during P3. Correspondingly, the apparent out-of-phase interannual relationship between TBV and TCF over different subregions causes a weak correlation between TBV and total TCF during both $\mathrm{P} 1$ and $\mathrm{P} 3$. In contrast, during $\mathrm{P} 2$, there is a clear southeast-northwest dipole pattern correlation between TBV and TCF. There appears to be a relatively consistent negative correlation pattern over the main development region of the WNP, resulting in a strong TBV-TCF association.

The total TCFs over the CENP and NATL basins both have a close interannual relationship with TBV during P1 and $\mathrm{P} 3$ as shown in Fig. 2, which is also reflected in a more consistent negative basinwide correlation between them compared to that during P2 (Fig. 3). In contrast, during P2, there is an insignificant correlation between TBV and TCF over the CENP and NATL basins (Fig. 2) that is mainly due to a mixture of positive and negative spatial correlations over these two basins as seen in Figs. 3e and 3h. Also shown in Fig. 3, the entire NATL basin TCF has a more consistent correlation with TBV during P1 and P3 (especially during P1), compared to that during P2. The positive correlation in the western Caribbean is weak in P2 and becomes stronger in P1 and P3, which relates to TCs making landfall in Central America and Mexico. The largest correlations in P3 over the NATL basin (and in any of the three basins) are observed in the western Caribbean. The Pacific region between $90^{\circ}$ and $100^{\circ} \mathrm{W}$ (close to Central America and Mexico) also shows a similar trend. These findings indicate that this subregion (on both sides of Central America) is modulated similarly by TBV, as opposed to the eastern NATL, which shows areas of both positive and negative correlations. Additional investigation of this relationship will be explored in future work.

\section{Importance of large-scale environmental parameters}

Increased lower-tropospheric vorticity, weak VWS, high midlevel relative humidity, warm SST, and large potential intensity (PI) have been documented in previous studies to be 
TABLE 1. Correlations between transbasin variability (TBV) and TC frequency (TCF), as well as environmental factors, including potential intensity (PI), lower-tropospheric vorticity (VOR), vertical wind shear (VWS), and 600-hPa relative humidity (RHUM) averaged over main development regions during 1979-97 (first value in each cell), 1998-2008 (second value), and 2009-19 (third value). Boldface font indicates that the correlation is significant at the $95 \%$ confidence level.

\begin{tabular}{lccccc}
\hline \hline & TBV-TCF & TBV-PI & TBV-VOR & TBV-VWS & TBV-RHUM \\
\hline WNP & $-0.02 /-\mathbf{0 . 6 7} /-0.40$ & $\mathbf{0 . 5 6} / 0.36 /-0.41$ & $-\mathbf{0 . 7 3} /-\mathbf{0 . 9 1} /-\mathbf{0 . 8 0}$ & $-\mathbf{0 . 7 9} /-0.28 / 0.11$ & $0.37 / 0.19 / 0.49$ \\
CENP & $-\mathbf{0 . 5 2} /-0.42 /-\mathbf{0 . 8 9}$ & $-0.43 /-\mathbf{0 . 7 9} /-\mathbf{0 . 8 8}$ & $-0.41 /-0.13 /-0.54$ & $\mathbf{0 . 6 8} / 0.59 / \mathbf{0 . 8 4}$ & $-\mathbf{0 . 7 1} /-0.23 /-0.06$ \\
NATL & $\mathbf{0 . 5 7} / 0.08 / \mathbf{0 . 6 5}$ & $0.31 /-0.21 / 0.42$ & $\mathbf{0 . 7 1} / 0.44 / \mathbf{0 . 6 3}$ & $-0.24 /-0.24 /-0.30$ & $0.07 / 0.27 / \mathbf{0 . 7 6}$ \\
\hline
\end{tabular}

favorable factors for TC genesis (Gray 1979; McBride 1981; Emanuel and Nolan 2004). The PI is thought to be a theoretical upper bound of TC intensity under given specific environmental thermodynamic conditions and has also been shown to impact TC genesis (Emanuel and Nolan 2004; Murakami et al. 2011). Details on the computation of PI can be found in Bister and Emanuel (2002), and the computation code can be obtained at ftp://texmex.mit.edu/pub/emanuel/TCMAX/. In this section, decadal changes in the interannual TBV-TCF relationship over the WNP, CENP, and NATL basins are further examined based on changes in large-scale environmental factors associated with TBV. In this section, the TCF-TBV correlation is explained by a large-scale environmental factor (e.g., vorticity), only if both the TBV-factor correlation (Table 1) and the TCF-factor correlation (Table 2) are significant.

\section{a. Changes in the relationship between $T B V$ and environmental parameters over the WNP basin}

There are significant negative correlations between TBV and lower-tropospheric vorticity over the WNP, especially over its southeastern region, during all three subperiods (Table 1). We further find that the impacts from VWS and PI oppose that induced by lower-tropospheric vorticity, thus leading to an insignificant relationship between TCF and all environmental factors and an insignificant modulation of TBV on TCF over the WNP during P1 (Tables 1 and 2). By contrast, lower-tropospheric vorticity associated with TBV appears to play a more important role in modulating TCF during P2, while other factors have no significant linkage with TBV (Tables 1 and 2). Similar to $\mathrm{P} 2$, there is a relatively weak negative correlation between TBV and lower-tropospheric vorticity and a relatively weak positive correlation between TCF and lowertropospheric vorticity during $\mathrm{P} 3$. These changes appear to be one of the main reasons causing weak decadal changes in the interannual TBV-TCF relationship from $\mathrm{P} 2$ to $\mathrm{P} 3$.

Figure 4 shows the correlation pattern between TBV and SST/PI during each of the three subperiods. There are decadal changes in the interannual relationship between TBV and SST/PI over the WNP basin. There are positive correlations over the WNP during P1 (Figs. 4a,b), leading to positive correlations between TBV and PI over the whole WNP basin (Table 1). The positive correlation pattern is weak in $\mathrm{P} 2$ and becomes negative during P3 (Figs. 4c-f). Local PI does not appear to exert a significant direct impact on TCF for the full WNP during any of the three subperiods (Table 2). Local PI associated with SST appears to play a limited role in WNP TCF changes.

Decadal correlation changes do occur between lowertropospheric vorticity and TBV for the other two subregions. The correlation pattern is very similar during the three subperiods but is relatively stronger during $\mathrm{P} 1$ and $\mathrm{P} 2$. Generally, negative correlations between lower-tropospheric vorticity and TBV are focused in the southern part of the WNP during $\mathrm{P} 1$, across most of the WNP expect for the northwestern part during P2 and in the southeastern WNP during P3. Decadal changes in the correlation between TBV and lower-tropospheric vorticity seem to link with TCF changes associated with TBV. There is a consistent basinwide negative correlation between TBV and VWS before 1998 (Fig. 5b), indicating that changes in VWS associated with TBV were conducive for TCs over the whole WNP basin. After 1998, the correlation map between VWS and TBV shows a southeast-northwest oriented pattern-a breakdown of the basinwide pattern observed during P1 (Figs. 5e,h). The correlation pattern between midlevel relative humidity and TBV is characterized by a zonal dipole for P1 and P2 (Figs. 5c,f), which appears to have little impact on either the meridional dipole pattern of TC genesis in $\mathrm{P} 1$ or the basinwide pattern of TC genesis in P2. Given the lack of statistical significance during P3, midlevel relative humidity modulations likely plays a limited role in TC genesis in the WNP (Fig. 5i).

\section{b. Changes in the relationship between TBV and environmental parameters over the CENP basin}

The significant TBV-TCF correlation in the CENP during P1 appears to be primarily due to VWS and midlevel relative humidity (Tables 1 and 2). Although TBV correlates significantly with PI and VWS during P2 (Table 1), these two factors

TABLE 2. As in Table 1, but for correlations between TC frequency (TCF) and environmental factors, including potential intensity (PI), lower-tropospheric vorticity (VOR), vertical wind shear (VWS), and 600-hPa relative humidity (RHUM).

\begin{tabular}{lccrr}
\hline \hline & TCF-PI & TCF-VOR & TCF-VWS & TCF-RHUM \\
\hline WNP & $0.30 / 0.15 / 0.15$ & $0.35 / \mathbf{0 . 6 9} / 0.58$ & $0.01 / 0.06 / 0.31$ & $0.10 /-0.07 / 0.30$ \\
CENP & $0.25 / 0.59 / \mathbf{0 . 9 3}$ & $0.03 / 0.40 / 0.57$ & $-\mathbf{0 . 4 3} /-0.21 /-\mathbf{0 . 7 5}$ & $\mathbf{0 . 5 1} / 0.31 /-0.13$ \\
NATL & $0.42 / \mathbf{0 . 7 1} / 0.25$ & $\mathbf{0 . 5 3} / 0.31 / \mathbf{0 . 6 6}$ & $-\mathbf{0 . 6 4} /-\mathbf{0 . 6 6} /-\mathbf{0 . 7 3}$ & $0.13 / 0.23 / \mathbf{0 . 6 2}$ \\
\hline
\end{tabular}


(a) Cor.TBV-SST 1979-1997

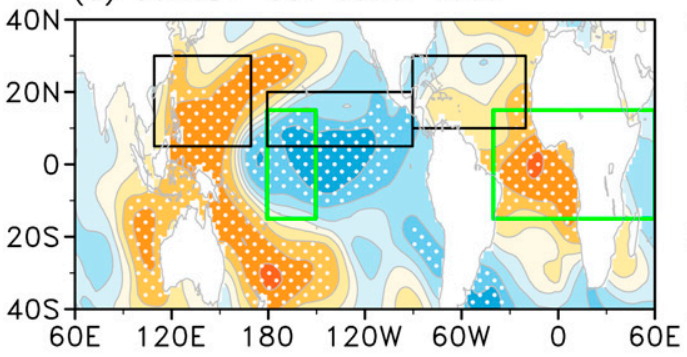

(c) Cor.TBV-SST 1998-2008



(e) Cor.TBV-SST 2009-2019

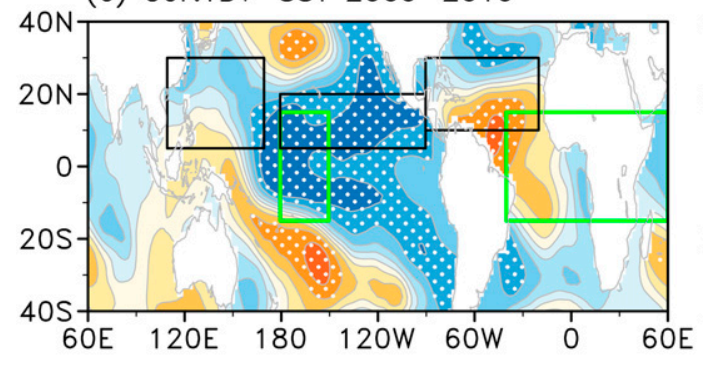

(b) Cor.TBV-PI 1979-1997

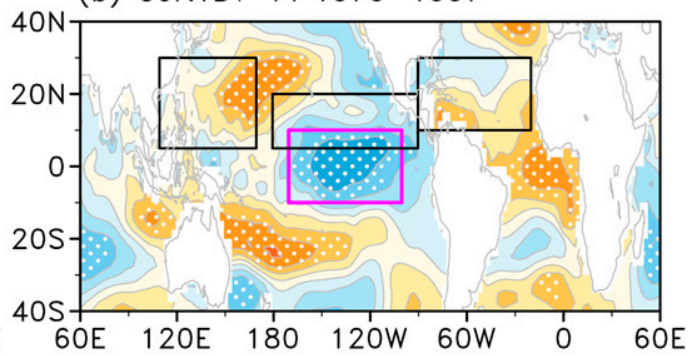

(d) Cor.TBV-PI 1998-2008



(f) Cor.TBV-PI 2009-2019

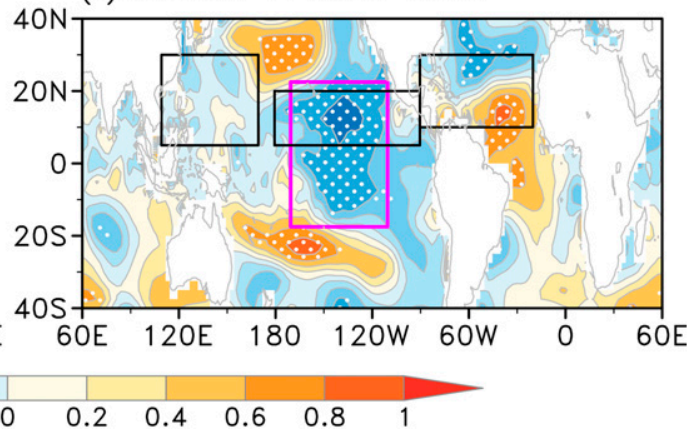

FIG. 4. Correlation between the TBV index and (left) SST and (right) potential intensity (PI) during (a),(b) 197997, (c),(d) 1998-2008, and (e),(f) 2009-19. The green and magenta boxes denote the definition of TBV and the region most significantly affected by PI, respectively. The divided subregions are shown with black boxes. The white dots represent the values that are significant at the $95 \%$ confidence level.

do not show a significant response to TCF and thus a weak correlation between TBV and TCF (Table 2). By contrast in P3 over the CENP basin, the enhanced TBV-VWS association is responsible for changes in TCs over the whole CENP with positive (negative) correlations between TBV and VWS (TCF) (Table 1).

As shown in Fig. 4, the CENP basin has decadal changes in the interannual relationship between TBV and SST/PI. The areas with positive (negative) correlations become meridionally narrow (broader) over the tropical western (centraleastern) Pacific in P3 compared with P1. Additionally, during $\mathrm{P} 1$, the correlation pattern is characterized by a typical eastern Pacific (EP) ENSO-like pattern, while appearing qualitatively like a tropical central Pacific (CP) ENSO-like correlation pattern during P2. During P3, there is a mixed tropical centraleastern ENSO-like pattern. During P1, there is a significant correlation $(r=-0.52)$ between TBV and the EP-ENSO index, but there is an insignificant correlation $(r=-0.32)$ between TBV and the CP-ENSO index. The CP-ENSO and
EP-ENSO indices here are calculated following the definitions proposed by Sullivan et al. (2016). By contrast, TBV correlates significantly ( $r=-0.93)$ with the CP-ENSO index but shows an insignificant relationship $(r=-0.16)$ with the EP-ENSO index during P2. In P3, CP-ENSO and EP-ENSO indices both correlate significantly with TBV. This further illustrates decadal changes of the central-eastern Pacific SST pattern associated with TBV. When examining the local relationships in Tables 1 and 2, local PI appears to significantly affect total CENP TCs during P3, since there is a consistent basinwide correlation between local PI and TBV (Fig. 4f).

During these three subperiods, there is a meridional dipole in correlations between TBV and lower-tropospheric vorticity (Figs. 6a,d,g), with a positive (negative) correlation over the northern (southern) part of the eastern CENP basin. Over the main development region, there is a positive correlation during $\mathrm{P} 1$ and P2 with a northwest-southeast dipole correlation pattern occurring during P3. These correlations all oppose the TBV-TCF correlation pattern (Figs. 3 and 6). TBV-related lower-tropospheric 
(a) $850 \mathrm{hP}$ VOR 1979-1997

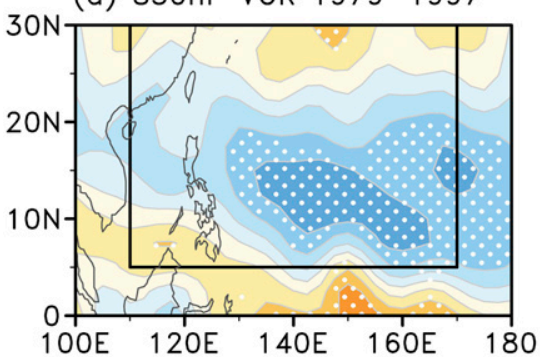

(d) $850 \mathrm{hP}$ VOR 1998-2008

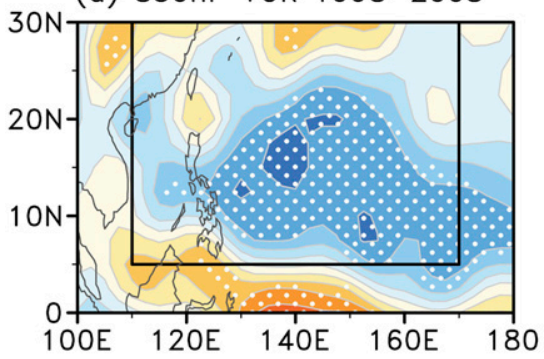

(g) $850 \mathrm{hP}$ VOR 2009-2019

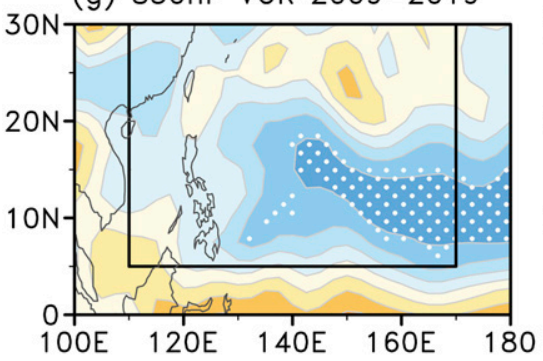

(b) VWS 1979-1997

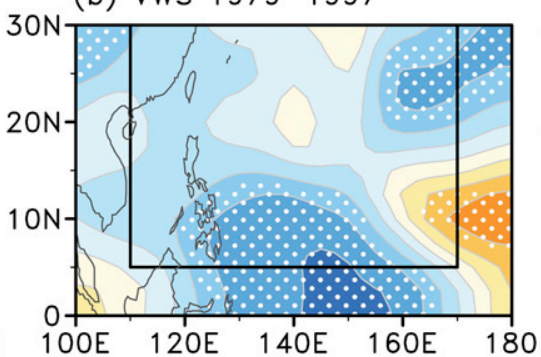

(e) VWS 1998-2008



(h) VWS 2009-2019

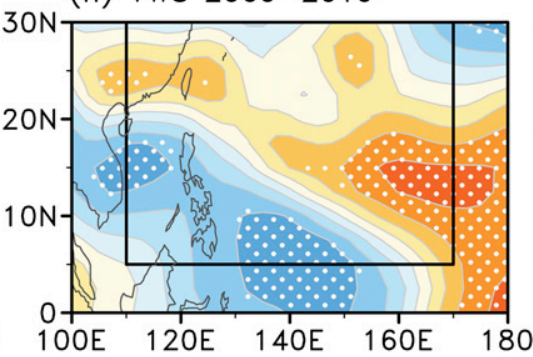

(c) 600hPa RHUM 1979-1997



(f) $600 \mathrm{hPa}$ RHUM 1998-2008

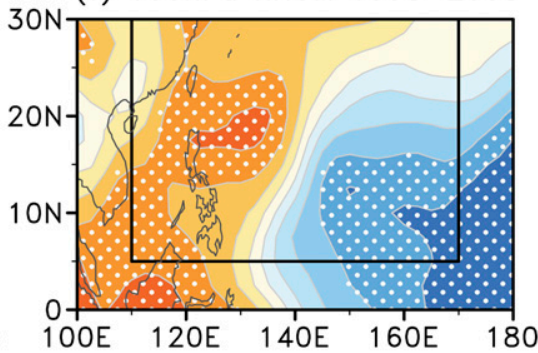

(i) $600 \mathrm{hPa}$ RHUM 2009-2019



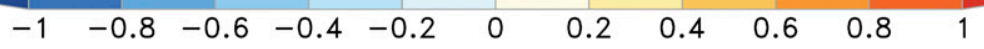

FIG. 5. Correlations between the TBV index and lower-tropospheric relative vorticity (VOR) at $850 \mathrm{hPa}$ over the extended boreal summer (May-October) during (a) 1979-97, (d) 1998-2008, and (g) 2009-19 for the WNP basin. (b),(e),(h) and (c),(f),(i) As in (a), (d), and (g), but for vertical wind shear (VWS) and 600-hPa relative humidity (RHUM), respectively. The black box represents the main development region. The dots indicate that the correlation is significant at the $95 \%$ confidence level.

vorticity contributes little to the significant interannual relationship between TC counts over the CENP and TBV during all three subperiods. Figures $6 \mathrm{~b}, 6 \mathrm{e}$, and $6 \mathrm{~h}$ show a correlation dipole pattern between TBV and VWS, with negative (positive) correlations over the northern (southern) part of the whole CENP basin during all three subperiods. Positive correlations cover the main development region during P3 while they are concentrated in the southern portion of the region during P1 and P2. In summary, we find that changes in the VWS-associated TBV are consistent with decadal changes in the TBV-TCF relationship, implying an important role for VWS associated with TBV in causing decadal changes in the TBV-TCF relationship over the CENP basin.

\section{c. Changes in the relationship between $T B V$ and environmental parameters over the NATL basin}

Weaker lower-tropospheric vorticity appears to be the driving factor behind the negative impact of TBV on Atlantic TC counts (Tables 1 and 2). Lower-tropospheric vorticity and midlevel humidity are likely two important contributors during P3. VWS has a significant correlation with TCF during all three subperiods, consistent with previous studies on the importance of VWS changes in modulating TC counts over the NATL basin (DeMaria 1996; Frank and Ritchie 2001; Knaff et al. 2004; Gray 1984; Goldenberg and Shapiro 1996; Iizuka and Matsuura 2009; Klotzbach 2011).

As shown in Fig. 4, the areas with a positive correlation between SST over the Atlantic and TBV are located over the tropical Atlantic $\left(20^{\circ} \mathrm{S}-20^{\circ} \mathrm{N}\right)$ during both $\mathrm{P} 1$ and $\mathrm{P} 3$, thus potentially impacting TC genesis over the NATL basin. The direct impact of SST in this study is measured by PI, which shows a similar distribution to SST. The insignificant correlations between TBV and PI during all three subperiods is mainly due to the dipolar distribution of PI over the NATL basin (Figs. 4b,d,f).

We observe a mostly positive correlation over the main development region between TBV and lower-tropospheric 
(a) $850 \mathrm{hP}$ VOR $1979-1997$

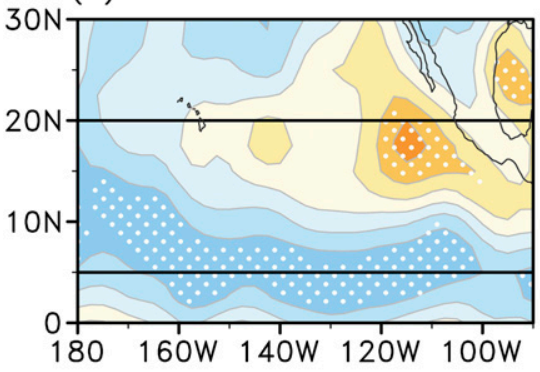

(d) $850 \mathrm{hP}$ VOR 1998-2008

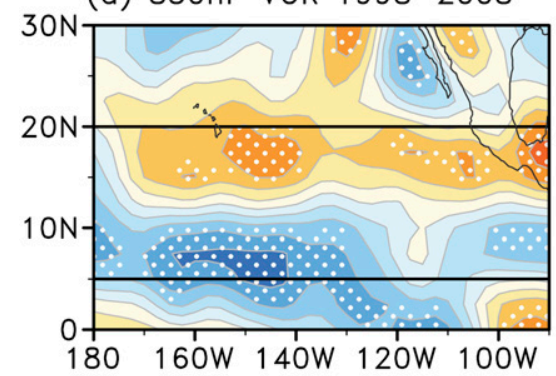

(g) $850 h P$ VOR 2009-2019

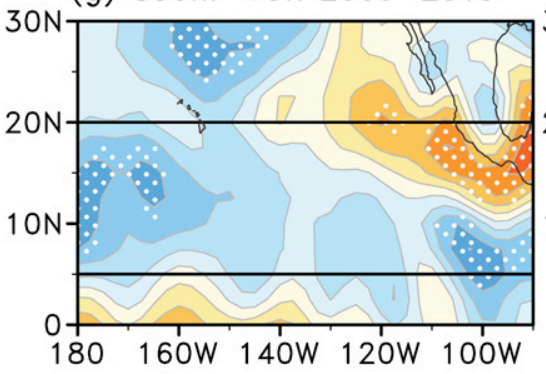

(b) VWS 1979-1997



(e) VWS 1998-2008



(h) VWS 2009-2019

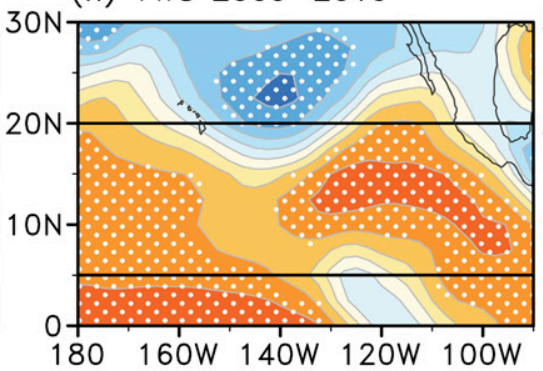

(c) $600 \mathrm{hPa}$ RHUM $1979-1997$

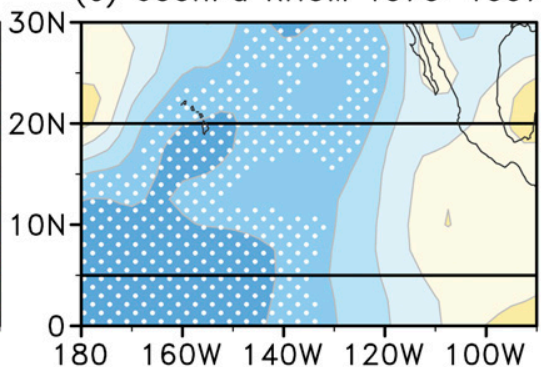

(f) $600 \mathrm{hPa}$ RHUM 1998-2008

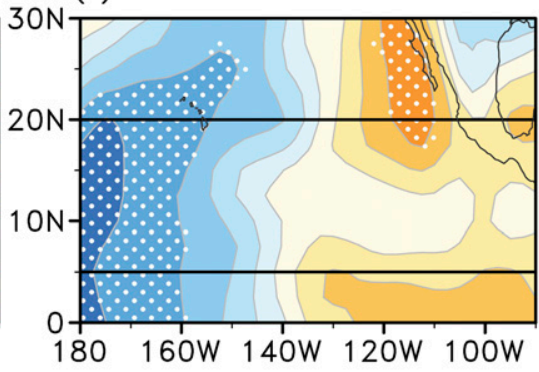

(i) $600 \mathrm{hPa}$ RHUM 2009-2019

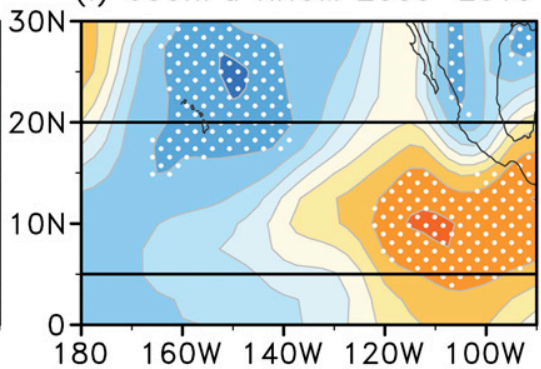
$\begin{array}{lllllllllll}-1 & -0.8 & -0.6 & -0.4 & -0.2 & 0 & 0.2 & 0.4 & 0.6 & 0.8 & 1\end{array}$

FIG. 6. As in Fig. 5, but for the CENP basin.

vorticity during P1 and P3 (Figs. 7a,g). In contrast, during P2, the correlations are primarily positive over the southern portion of the main development region, with negative correlations over the northern portion of the main development region (Fig. 7d). When combined with the results presented in Fig. 2, the lower-tropospheric vorticity associated with the TBV appears to be an important factor causing decadal changes in the interannual relationship between TCF and TBV. Similar to what was found for lower-tropospheric vorticity, the TBV-VWS relationship also has a positive correlation over the southern part of the main development region and a negative correlation over the northern part of the main development region, while the relationship appears somewhat weaker during P2. The correlation maps between TBV-VWS and TBV-TCF during P2 look very similar (Figs. 3 and 7e). Also shown in Fig. 7i, there is a basinwide positive correlation between midlevel moisture and TBV during P3, which may significantly affect TCF. By contrast, the relationship between TBV and NATL midlevel relative humidity displays a zonal dipole pattern, which is inconsistent with observed TC formations as shown in Figs. $3 \mathrm{~g}$ and $3 \mathrm{~h}$.

\section{d. Potential role of changes in SSTAs associated with TBV driving changes in the large-scale environment}

As suggested by previous studies on the combined impacts of SST anomalies in different oceans on changes in environmental parameters (Zhan et al. 2014; Cao et al. 2018; Liu et al. 2019; Wu et al. 2020), decadal changes in the correlations of western Pacific, eastern/central Pacific, and Indian Ocean SST appear to be the main reason for the observed environmental changes over the WNP. There is a significant difference between western Pacific and central-eastern Pacific SST between periods P1 and P2 (Figs. 4a,c). Due to the significant zonal gradient in SST, enhanced lower-tropospheric easterlies occur over the WNP, leading to an anticyclonic circulation anomaly as well as reduced lower-tropospheric vorticity (Figs. 5a,d). Midlevel relative humidity also is characterized by a zonal dipole distribution with water vapor transport induced by 
(a) $850 \mathrm{hP}$ VOR $1979-1997$

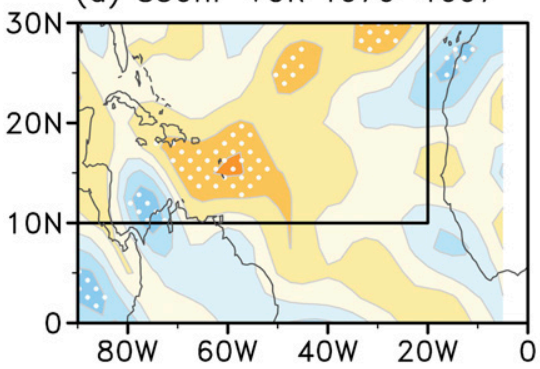

(d) $850 \mathrm{hP}$ VOR $1998-2008$



(g) $850 \mathrm{hP}$ VOR $2009-2019$

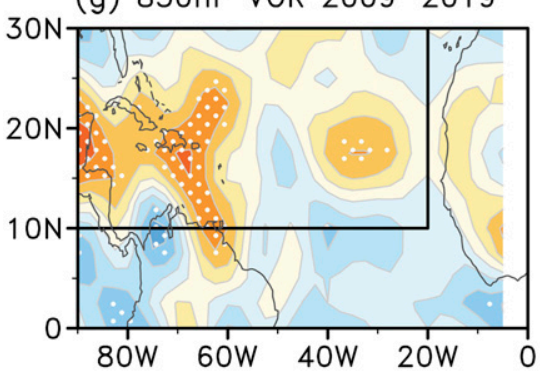

(b) VWS 1979-1997

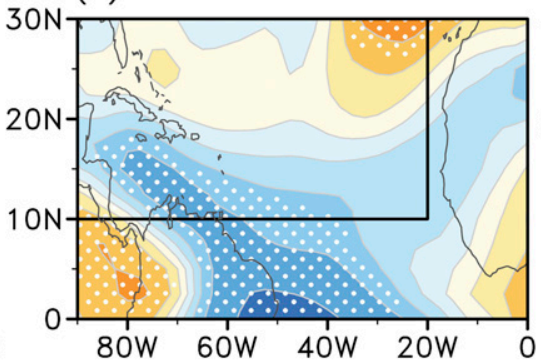

(e) VWS 1998-2008

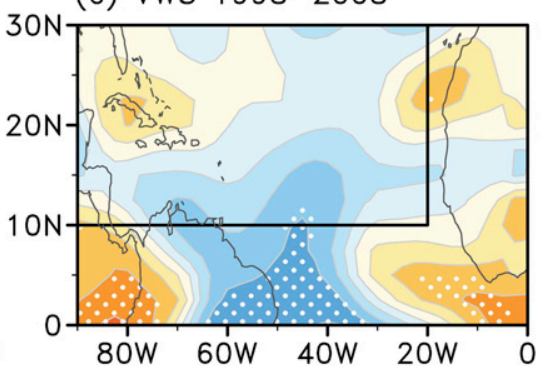

(h) VWS 2009-2019



(c) 600hPa RHUM 1979-1997

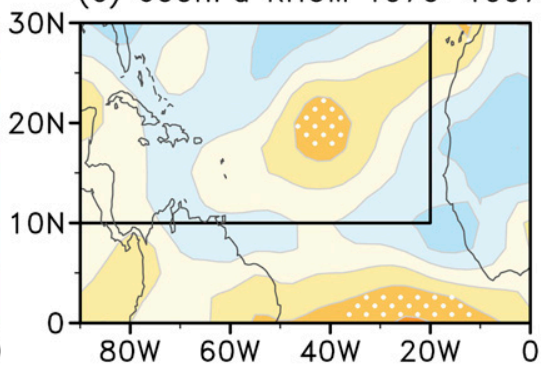

(f) $600 \mathrm{hPa}$ RHUM 1998-2008

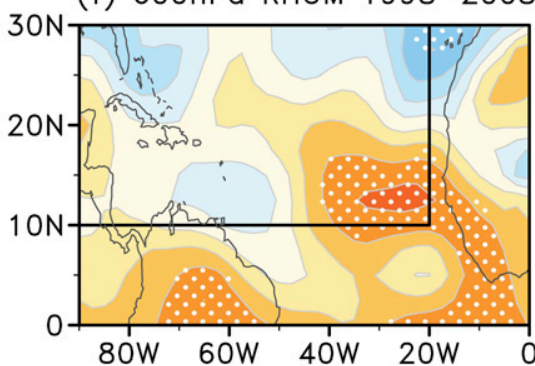

(i) $600 \mathrm{hPa}$ RHUM 2009-2019

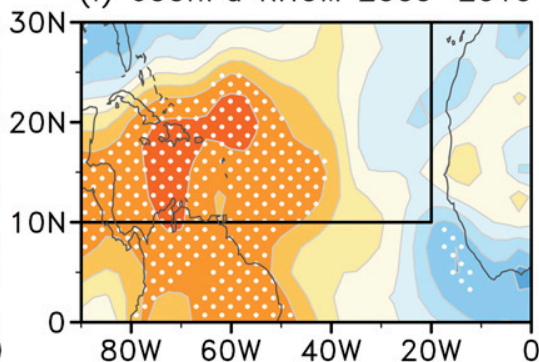

\section{$\begin{array}{lllllllllll}-1 & -0.8 & -0.6 & -0.4 & -0.2 & 0 & 0.2 & 0.4 & 0.6 & 0.8 & 1\end{array}$}

FIG. 7. As in Fig. 5, but for the NATL basin.

anomalous low-level easterlies (Figs. 5c,f). The SST correlation difference between the western and central-eastern Pacific extends northward to the subtropics, weakening the westerlies associated with the anticyclonic circulation and resulting in a basinwide negative VWS correlation pattern during P1 (Figs. 4a and $5 \mathrm{~b}$ ). In contrast, this SST pattern is concentrated in the tropics during $\mathrm{P} 2$ and $\mathrm{P} 3$, leading to a southeast-northwestoriented VWS anomaly pattern accompanied by a lowertropospheric anticyclonic circulation (Figs. 4c,e and 5e,h). Over the Indian Ocean, the negative correlation between TBV and SST during $\mathrm{P} 1$ and $\mathrm{P} 3$ is relatively larger than that during $\mathrm{P} 2$. As discussed in Zhan et al. (2014), the SST gradients between the tropical Indian Ocean and the western Pacific during P1 and P3 (P2) are stronger (weaker), leading to an enhanced (weakened) westerly low-level cyclonic circulation anomaly, which is favorable (unfavorable) for TC genesis over the southwestern WNP (Fig. 4). These changes then result in more zonally consistent (zonally varying) changes in TC counts over the WNP basin during $\mathrm{P} 2$ (P1 and P3).
The meridional extent of SST anomalies over the central and eastern Pacific associated with the TBV also impacts WNP TC frequency. Along with the PDO phase change from warm to cold (from P1 to P2), the central-eastern Pacific SST anomaly signal becomes meridionally broader (Grassi et al. 2012), leading to a poleward shift of WNP TC location via enhancement of the Hadley circulation (Nguyen et al. 2013; Sharmila and Walsh 2018; Zhao et al. 2019b). Hence, large-scale environmental factors (e.g., lower-tropospheric vorticity) favorable (or unfavorable) for TC genesis extend farther poleward in P2, leading to a consistent TCF change over the whole WNP. Given that there is no obvious SST anomaly difference between the western Pacific and the central-eastern Pacific during $\mathrm{P} 3$, especially north of $10^{\circ} \mathrm{N}$ (Fig. 4e), the poleward shift of WNP TCs is inhibited by weak horizontal winds induced by a weak zonal gradient. Large-scale environmental parameters associated with SST differences between the Indian Ocean and the western Pacific as well as the meridional extent of the central-eastern Pacific SST anomalies are responsible for 
decadal changes in the relationship between TBV and total TCF over the WNP.

Decadal changes in the ENSO pattern may be the reason for the observed environmental changes over the CENP basin. A typical CP ENSO pattern is observed during $\mathrm{P} 2$, while $\mathrm{P} 1$ and $\mathrm{P} 3$ are characterized by a more EP ENSO pattern (Figs. 4a,c,e). Lower-tropospheric westerly winds have broader zonal coverage during P2 due to the negative SST correlation over the central Pacific, which display a dipolar distribution of lower-tropospheric vorticity and midlevel relative humidity (Figs. 6d,e,h). In contrast, lower-tropospheric westerly winds are weaker and contracted over the eastern CENP during P1 and P3, leading to a dipolar distribution over the eastern CENP (Figs. 6a,g). Due to the SSTA difference between the western Pacific and the central-eastern Pacific as well as the SSTA difference between the centraleastern Pacific and the Atlantic, there is an easterly lowertropospheric wind anomaly over the western CENP and a westerly lower-tropospheric wind anomaly over the eastern CENP during P1, leading to a basinwide negative midlevel humidity correlation pattern (Fig. 6c). During P2 and P3, the relatively weak lower-tropospheric easterly flow induced by the small SST gradient between the western Pacific and centraleastern Pacific only covers the western CENP during P2 and P3, leading to a zonal dipole distribution in midlevel humidity (Figs. 6f,i). P3 has a broader meridional negative SST correlation over the central-eastern Pacific when compared with P1 and P2, causing broader lower-tropospheric westerly winds as well as positive VWS (Figs. 6b,e,h).

Over the NATL basin, decadal changes in local SST appear to play an important role in decadal changes in correlations between environmental factors and TBV. During P2, the region that positively correlates with SST is primarily focused over $20^{\circ} \mathrm{S}-10^{\circ} \mathrm{N}$ (Fig. $4 \mathrm{c}$ ), and there is no obvious meridional SST gradient over the NATL basin. This SST pattern produces a relatively weak cyclonic circulation in the southern NATL close to the equator, leading to a dipolar distribution of lowertropospheric vorticity as well as VWS (Fig. 7d). In contrast, due to the broader meridional extent of the positive SST correlation during P1 and P3, lower-tropospheric westerlies over the NATL induced by the SST gradient between the central-eastern Pacific and NATL basin is stronger, thus leading to a decrease in VWS over the southern NATL (Figs. 4a,e and 7a,b,g,h). P1 and P3 have a similar lower-tropospheric vorticity pattern (Figs. 4a,c and $7 \mathrm{~g}, \mathrm{i})$. In summary, TBV-related lower-tropospheric vorticity appears to be the most important factor causing decadal changes in the interannual TBV-TCF relationship over the NATL. TBVrelated midlevel relative humidity likely plays a role in modulating the interannual relationship between TBV and NATL TCF during P3.

\section{Plausible physical mechanisms}

We find that decadal changes in the relationship between TBV and total TCF are mainly due to changes in environmental factors associated with TBV. Although there is a strong association between TBV and ENSO, the way that TBV influences the large-scale environment and how that then impacts its association with TCF remains unclear. Prior studies have suggested that TBV has a strong association with ENSO (Park et al. 2017; Choudhury et al. 2017). Indeed, there is a significant correlation $(r=-0.74)$ between TBV and the Niño3.4 index during our study period from 1979 to 2019. As noted in section 3, there are three distinct regimes in the interannual relationship between TBV and TCF. In contrast, we do not find these decadal regimes for Niño-3.4 and TCF (Fig. 2b). Therefore, although TBV and ENSO share similar characteristics, TBV appears to more significantly impact total TCF over the three basins than ENSO does. In this section, we examine the distinct modulation of TCF by TBV and ENSO in these three ocean basins.

\section{a. Variability of $T B V$ on different time scales}

A power spectrum analysis highlights that TBV has distinct features from ENSO (Fig. 8). The power spectrum of the detrended TBV index shown in Fig. 8a indicates that the first peak in TBV has a period of $\sim 12.5$ years with a second peak period of $\sim 4.0$ years. The detrended TBV index is used here to remove the possible impact of global warming on changes in TBV over the period considered. A similar interannual period of $\sim 4.0$ years is found for the power spectrum of the detrended Niño-3.4 index, but there is no decadal periodicity observed for the detrended Niño-3.4 index (Fig. 8b). A significant interannual correlation between TBV and ENSO may arise from a similar in-phase interannual periodicity. We hypothesize that the TBV may be a decadal background state that modulates interannual changes in ENSO-like events. Using wavelet analyses (Figs. 8c,d) for the detrended TBV and Niño-3.4 indices, we find a distinct difference between the two indices, with decadal variability dominating TBV but interannual variability prevailing for ENSO. Moreover, there is an obvious decadal change in the dominant TBV period in Fig. 8c, with considerable decadal and interannual variability during both P1 and P3, but with decadal period variability tending to dominate during P2.

Given that there is not a complete separation between TBV and ENSO, we conduct an EOF analysis of tropical SST $\left(20^{\circ} \mathrm{S}-\right.$ $20^{\circ} \mathrm{N}, 0^{\circ}-360^{\circ} \mathrm{E}$ ), following previous studies (Kawamura 1994; Kao and Yu 2009). The first EOF mode shows an ENSO-like pattern, with cold SSTAs in the central-eastern Pacific and Indian Oceans and warm SSTAs over the western Pacific and Atlantic (Fig. 9a). The second EOF mode is characterized by a TBV-like pattern, with negative SSTAs in the central Pacific and positive SSTAs in the western Pacific, Atlantic, and Indian Oceans (Fig. 9b). In this study, the first two leading EOF modes are roughly used to describe the "pure ENSO" and "pure TBV" signals, accounting for $\sim 44 \%$ and $\sim 23 \%$ of the explained variance, respectively (Figs. 9a,b). We further reconstructed the TBV index (RTBV) (i.e., $\mathrm{RTBV}=1.0 \times \mathrm{PC} 1+0.52 \times \mathrm{PC} 2)$ using multiple linear regression with the first two leading PCs as the independent variables. In using this approach, we obtained a significant correlation $(r=0.70)$ between the reconstructed TBV index and the TBV index during the whole period investigated from 1979 to 2019 (Fig. 10). Since there is a stable linear relationship between the PCs and TBV, the relative contribution of PC1 and PC2 to TBV can be measured with their standard variance (STD). During 1979-97 and 2009-19, the STD of PC1 is much stronger than $\mathrm{PC} 2$, indicating the dominant role of pure 
(a) Spectrum analysis for detrended TBV

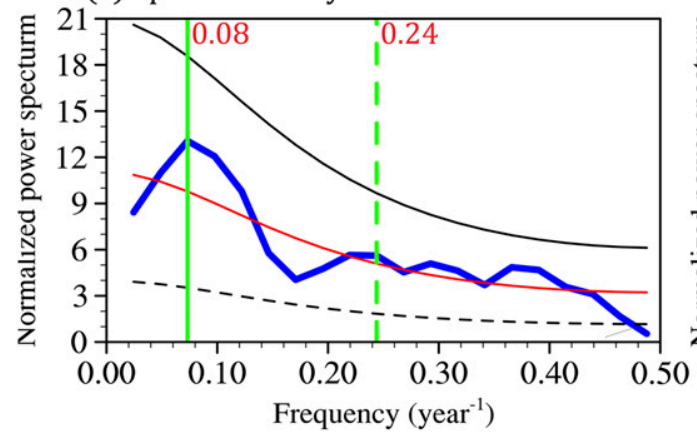

(c) Wavelet analysis for detrended TBV

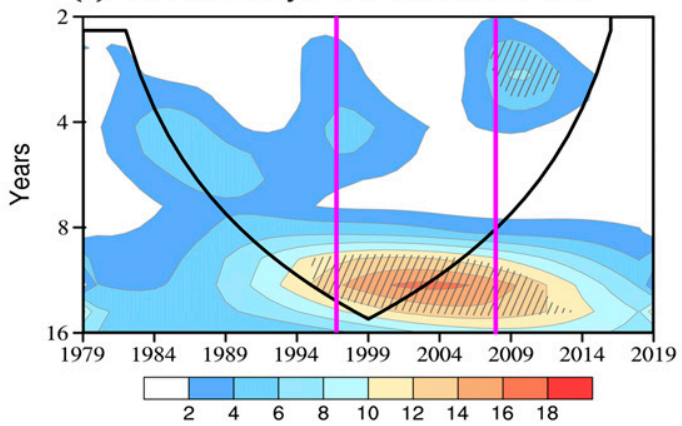

(b) Spectrum analysis for detrended Nino3.4

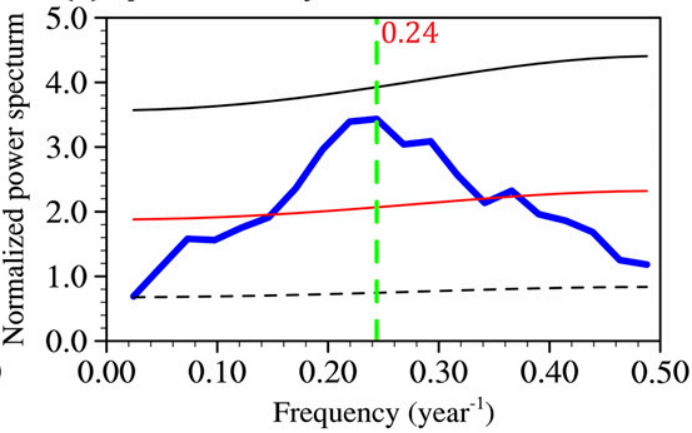

(d) Wavelet analysis for detrended Nino3.4



FIG. 8. Power spectrum analysis of boreal summer (May-October) (a) detrended TBV and (b) Niño-3.4 index from 1979-2019. The black lines indicate the confidence interval, and the red lines represent a red noise threshold. Wavelet analysis of boreal summer (c) detrended TBV and (d) Niño-3.4 index. The thick black contour designates the cone of influence where the edge effects might not be ignored (shown as a lighter shade), and the stripe denotes the $95 \%$ significance level against noise.

ENSO in raw TBV. In contrast, the STD of PC1 and PC2 amplitude are comparable during 1998-2008, indicating their relatively equal contributions to raw TBV during this 11-yr period (Fig. 9c).

We then use an 11-yr moving correlation between raw TBV and first two leading PCs to show that there are distinct decadal changes in the contribution of PC1 and PC2 to TBV (Fig. 9d). As shown in Fig. 9d, both PC1 and PC2 have significant interannual correlations with raw TBV before 1998, implying significant contributions of both the first and second EOF modes to the interannual variability of raw TBV during P1. Together with the larger variance for $\mathrm{PC} 1$ on interannual time scales (1.15 vs 0.63) (Figs. 9c and 10), the contribution from the first EOF mode appears to be more important in driving the interannual variability of TBV during P1. During 1998-2008, the correlation between TBV and PC2 decreases (Fig. 9d). Meanwhile, the interannual variance of PC1 is nearly comparable to the variance of $\mathrm{PC} 2$ ( 0.65 vs 0.57 , respectively) (Figs. $9 \mathrm{c}$ and 10). These results suggest comparable contributions from the first and second EOF modes to interannual changes in TBV during P2. Also shown in Fig. 9d is a significant correlation between PC1 and TBV but an insignificant correlation between PC2 and TBV during P3. This indicates a possible stronger impact of the first EOF mode on the interannual variability of TBV during $\mathrm{P} 3$, which is confirmed by the amplitudes of their variances on interannual time scales for the reconstructed TBV (1.03 vs 0.59 ) (Fig. 10). This finding is also consistent with the observed interannual relationship between TBV-TCF and Niño-3.4-TCF over these three basins (Fig. 2).

\section{b. Contributions of pure TBV and pure ENSO to TCF over the WNP basin}

Figure 11 shows correlation patterns of PC1 and PC2 with global SST for the three subperiods. The correlation patterns of global SST associated with TBV during all three subperiods over the Pacific are similar to those associated with PC1 (Figs. 4a,c,e and 11a,c,e). There is no obvious change in the correlation pattern between SST and PC2 especially over the Pacific (Figs. 11b,d,f), further confirming the importance of the ENSO-like mode.

Correlations between $\mathrm{PC} 1$ and environmental parameters are similar to that between TBV and environmental parameters during $\mathrm{P} 1$ and $\mathrm{P} 3$ (Tables 1 and 3 ). We note that no factors associated with $\mathrm{PC} 2$ are found to be significantly correlated with WNP TCF, although WNP TCF is linked closely with TBV and PC2 during P2. TBV-related lower-tropospheric vorticity is an important factor for TC formation during $\mathrm{P} 2$, correlating significantly with P2 (at the $90 \%$ confidence level). We find a relatively comparable contribution from PC1 and PC2 to lower-tropospheric vorticity $(r=-0.47$ and $r=-0.57$, respectively). Moreover, the first and second EOF modes are both important contributors to the interdecadal modulation of 

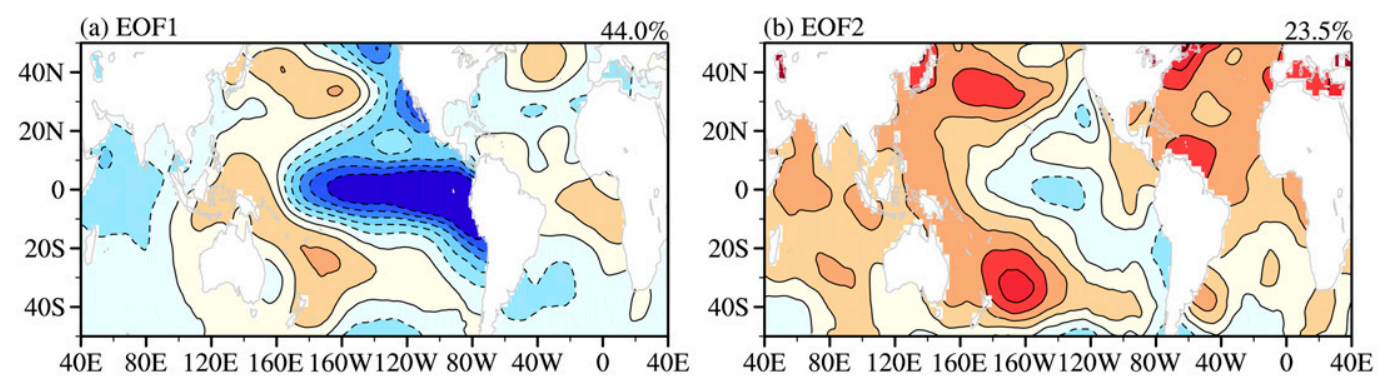

(c) PC1(solid)/PC2(dashed)

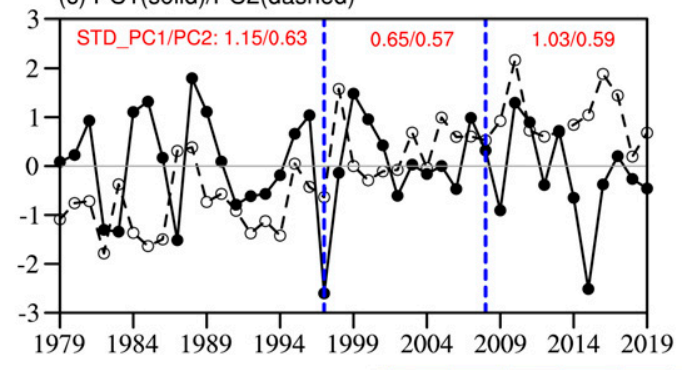

(d) $11 \mathrm{yr}$ correlation TBV-PC1(solid)/PC2(dashed)

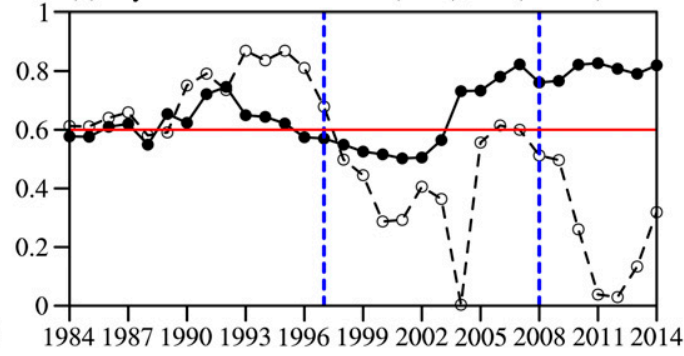

$\begin{array}{lllllllllll}-0.5 & -0.4 & -0.3 & -0.2 & -0.1 & 0 & 0.1 & 0.2 & 0.3 & 0.4 & 0.5\end{array}$

FIG. 9. Regression of the first two leading tropical SST EOF modes (a) PC1 and (b) PC2 on extended boreal summer (May-October) SST from 1979 to 2019. (c) Normalized time series of PC1 and PC2 (black) and their standard deviation during the three subperiods (red). (d) 11-yr running correlation between the TBV index and $\mathrm{PC} 1 / \mathrm{PC} 2$. The red line is the threshold for a significant correlation at the $95 \%$ confidence level.

the interannual TBV-TC relationship over the WNP basin. The contribution from PC2 appears to be more significant. This may be explained by ENSO-like interannual variability amplitude changes associated with PDO-like interdecadal variability contributing to the TBV decadal transition phase (1998-2008) (Imada and Kimoto 2009). The transition is closely associated with decadal changes in the PC2 (Fig. 9d).

\section{c. Contributions of pure TBV and pure ENSO to TCF over the CENP basin}

As discussed in section 4, decadal changes in TBV-TCF are due to the amplitude of lower-tropospheric westerlies associated with the zonal SST gradient between the tropical $\left(20^{\circ} \mathrm{S}-\right.$ $20^{\circ} \mathrm{N}$ ) central-eastern Pacific and Atlantic Ocean (Fig. 4). This gradient appears to be mostly affected by Atlantic Ocean SST. As shown in Fig. 11, the Atlantic SST anomaly associated with PC2 remains mostly unchanged during each of the three subperiods, indicating a limited role of the TBV-like mode in the decadal change of the interannual relationship between TBV and TCF. By contrast, the tropical Atlantic SST $\left(20^{\circ} \mathrm{S}-20^{\circ} \mathrm{N}\right)$ associated with $\mathrm{PC} 1$ displays obvious interdecadal changes with a dipole pattern during $\mathrm{P} 1$ and basinwide negative and positive patterns during P2 and P3, respectively (Figs. 11a,c,e). Although Atlantic SST associated with the TBV-like mode does not show significant decadal changes, it enhances SST differences between the central-eastern Pacific and the Atlantic Ocean during all subperiods. As a result, the correlation between TBV and CENP TCs during all subperiods are larger than that between ENSO and CENP TCs (Fig. 2).
As shown in Table 3, PC1-related VWS and PI play a critical role in modulating TCs over the CENP during P3 as demonstrated by the significant correlation between TCF over the CENP basin and $\mathrm{PC} 1$ during $\mathrm{P} 3(r=-0.69)$ and the significant correlations between both TCF and PC1 and both VWS and PI. In contrast, there is an insignificant correlation between PC1-related environmental factors and TCF over the CENP basin during P2, implying a limited role in the changes of factors associated with PC1 in TC genesis. Together with the weak correlation between



FIG. 10. Linear reconstructed TBV obtained with normalized PC1 and PC2 of the first two leading tropical SST EOF modes during 1979-2019. The labels at the top of the graph specify the linear-fit equations and the correlation coefficient between the reconstructed (RTBV) and the original TBV (OTBV). Two asterisks $(* *)$ indicate that the correlation is significant at the $95 \%$ confidence level. The labels at the bottom of the graph give the standard deviation of PC1 and PC2 during the three subperiods. 
(a) Cor.PC1-SST 1979-1997

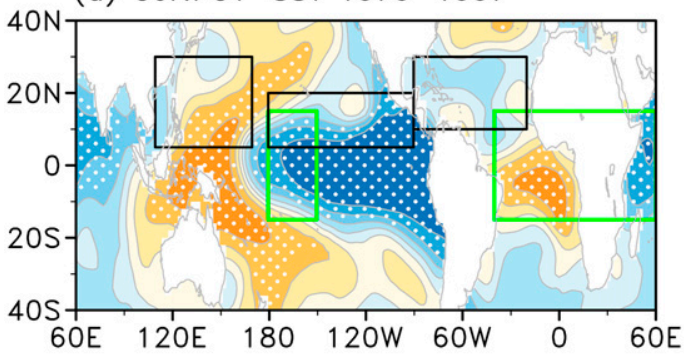

(c) Cor.PC1-SST 1998-2008

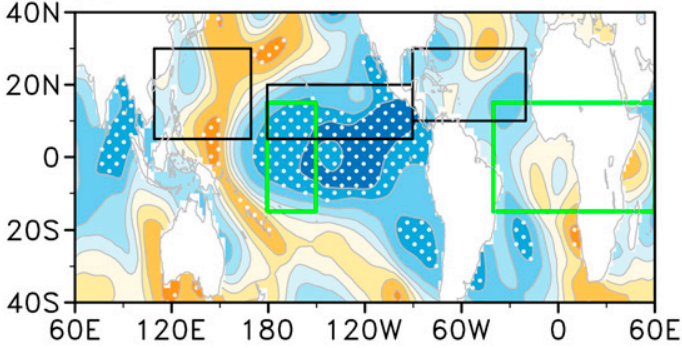

(e) Cor.PC1-SST 2009-2019

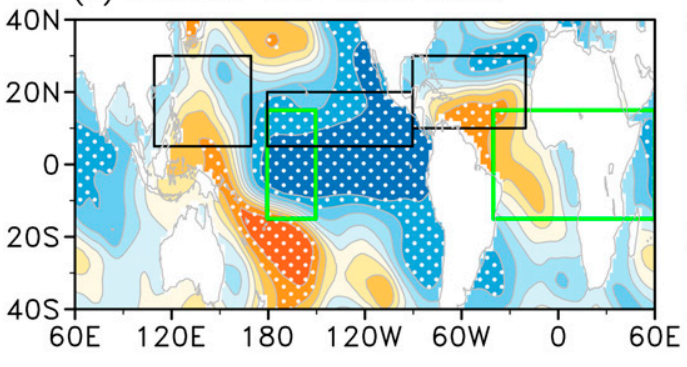

(b) Cor.PC2-SST 1979-1997

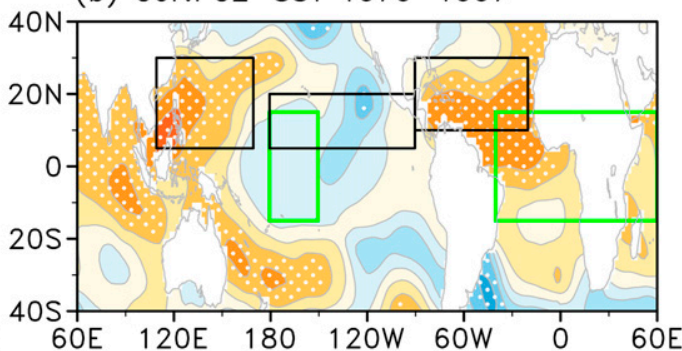

(d) Cor.PC2-SST 1998-2008

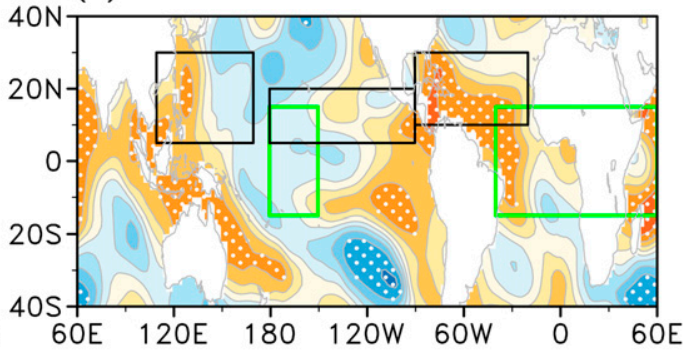

(f) Cor.PC2-SST 2009-2019

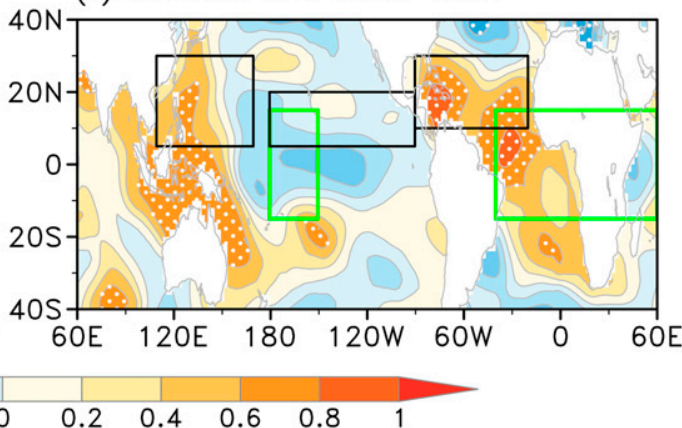

FIG. 11. Correlations between the PCs of the first two leading tropical SST EOF modes and SST over the extended boreal summer (May-October) during (a),(b) 1979-97, (c),(d) 1998-2008, and (e),(f) 2009-19. The dots indicate that the correlation is significant at the $95 \%$ confidence level. The black and green boxes are the main development regions and what is used to define the TBV index, respectively.

PC1 and environmental factors (Table 3), TCF has a weak correlation with $\mathrm{PC} 1$ and $\mathrm{PC} 2$ for $\mathrm{P} 2$ (Table 3). Although TCF over the CENP has an insignificant relationship with PC1 during P1, we do find a significant correlation between $\mathrm{PC} 2$ and TCs over the CENP basin $(r=-0.45)$. The significant contribution mainly arises from the VWS pattern associated with the TBV-like mode (PC2) that significantly modulates TCF over the CENP basin during $\mathrm{P} 1$, while the relatively weak dipolar $\mathrm{PC} 1-\mathrm{VWS}$ pattern

TABLE 3. As in Table 1, but for correlations between the PC1/PC2 index and TC frequency (TCF), as well as corresponding environmental factors, including potential intensity (PI), lower-tropospheric vorticity (VOR), vertical wind shear (VWS), and 600-hPa relative humidity (RHUM).

\begin{tabular}{lccccc}
\hline \hline & PC1-TCF & PC1-PI & PC1-VOR & PC1-VWS & PC1-RHUM \\
\hline WNP & $0.09 /-0.21 /-0.02$ & $0.08 / 0.09 /-0.14$ & $-0.42 /-0.47 /-\mathbf{0 . 6 9}$ & $-0.42 /-\mathbf{0 . 6 4} / 0.02$ & $\mathbf{0 . 6 6} / 0.47 / \mathbf{0 . 6 4}$ \\
CENP & $-0.26 /-0.43 /-\mathbf{0 . 6 9}$ & $-0.31 /-0.43 /-\mathbf{0 . 7 8}$ & $-\mathbf{0 . 8 8} /-\mathbf{0 . 6 3} /-\mathbf{0 . 7 3}$ & $\mathbf{0 . 4 7} / 0.26 / \mathbf{0 . 7 3}$ & $-\mathbf{0 . 5 6} /-0.01 /-0.36$ \\
NATL & $\mathbf{0 . 4 6} / 0.22 / \mathbf{0 . 7 5}$ & $-0.07 /-0.01 / 0.21$ & $\mathbf{0 . 6 4} / \mathbf{0 . 6 7 / 0 . 7 8}$ & $-0.40 /-0.32 /-0.45$ & $0.14 / 0.15 / \mathbf{0 . 7 9}$ \\
& & & & \\
& PC2-TCF & PC2-PI & PC2-VOR & PC2-VWS & PC2-RHUM \\
\hline WNP & $-0.20 /-\mathbf{0 . 7 1} /-0.56$ & $\mathbf{0 . 5 7} /-0.17 / 0.35$ & $-\mathbf{0 . 6 2} /-0.57 /-\mathbf{0 . 7 2}$ & $-\mathbf{0 . 6 6} / 0.03 /-0.19$ & $-0.09 /-0.36 /-0.10$ \\
CENP & $-\mathbf{0 . 4 5} /-0.10 /-0.49$ & $-0.33 /-0.38 /-0.39$ & $-0.05 / 0.16 /-0.45$ & $\mathbf{0 . 4 6} / 0.38 / 0.11$ & $-0.36 /-0.23 /-0.33$ \\
NATL & $0.37 / 0.06 / 0.53$ & $\mathbf{0 . 6 2} /-0.01 / 0.27$ & $\mathbf{0 . 4 5} /-0.06 / 0.24$ & $-0.09 /-0.13 /-0.39$ & $0.16 / 0.53 / 0.20$ \\
\hline
\end{tabular}


over the CENP shows a limited role. In contrast, the PC1-VWS correlation shows an apparent dipolar pattern during P2 and an almost basinwide pattern during $\mathrm{P} 3$, consistent with the correlation map between TBV and VWS. Together with the consistent impact of the TBV-like mode, this implies a dominant role of the ENSO-like mode in changing the interannual relationship between TCF over the CENP during P2 and P3. These analyses indicate that the first EOF (ENSO-like) mode is the dominant reason for decadal changes in the relationship between CENP TCF and TBV.

\section{d. Contributions of pure TBV and pure ENSO to TCF over the NATL basin}

There is a robust PC2-SST interannual correlation pattern for the whole subperiod with a consistent enhanced relationship between the TBV-like mode and SST over the tropical Atlantic Ocean (Figs. 11b,d,f), implying a limited role of the TBV-like mode in decadal changes of the TBV-TCF relationship over the NATL basin. In contrast, the PC1-SST interannual correlation pattern shows an apparent decadal change, with a positive correlation between PC1 and tropical Atlantic basin SST during P1 and P3 (Figs. 11a,e) but with a negative correlation during P2 (Fig. 11c). Additionally, the interannual correlation map between the raw TBV index and SST shows a more consistency with the PC1-SST correlation pattern (Figs. 4 and 11) during each of the three subperiods.

As shown in Tables 1 and 3, the PC1-related lower-tropospheric vorticity appears to be a dominant factor impacting interdecadal changes of TCF over the NATL basin. We also find similar consistency on the importance of other large-scale factors associated with PC1 and TBV. There is also a significant correlation between TCF over the NATL basin and PC1 during both P1 and P3 ( $r=$ 0.46 and $r=0.75$ ), agreeing well with decadal changes in the TBV-TCF relationship over the NATL basin (Tables 1 and 3). This also further confirms that changes in the first EOF (ENSOlike) mode dominate decadal changes in the TBV-TCF relationship over the NATL basin.

\section{Discussion}

As shown above, there is an apparent decadal modulation of TBV on TCF over the WNP, CENP, and NATL basins, with an insignificant correlation during $\mathrm{P} 1$ and $\mathrm{P} 3$ and a significant correlation during P2 over the WNP basin. The opposite situation arises over the CENP and NATL basins, with a significant correlation during P1 and P3 and an insignificant correlation during P2 (Table 1). These changes are consistent with the association of large-scale factors with the TBV. Additional analyses suggest that lower-tropospheric vorticity associated with the TBV appears to be one of the most important factors causing decadal changes in the TBV-TCF relationship over the NATL and WNP basins, while VWS is one of the most important factors causing decadal changes in the TBV-TCF relationship in the CENP basin (Tables 1 and 2). These changes are largely explained by decadal changes in the TBV-like mode (PC1) and the ENSO-like mode (PC2) (Fig. 12).

The decadal changes in the amplitude of the ENSO-like mode (PC1) appear to dominate TBV and its associated
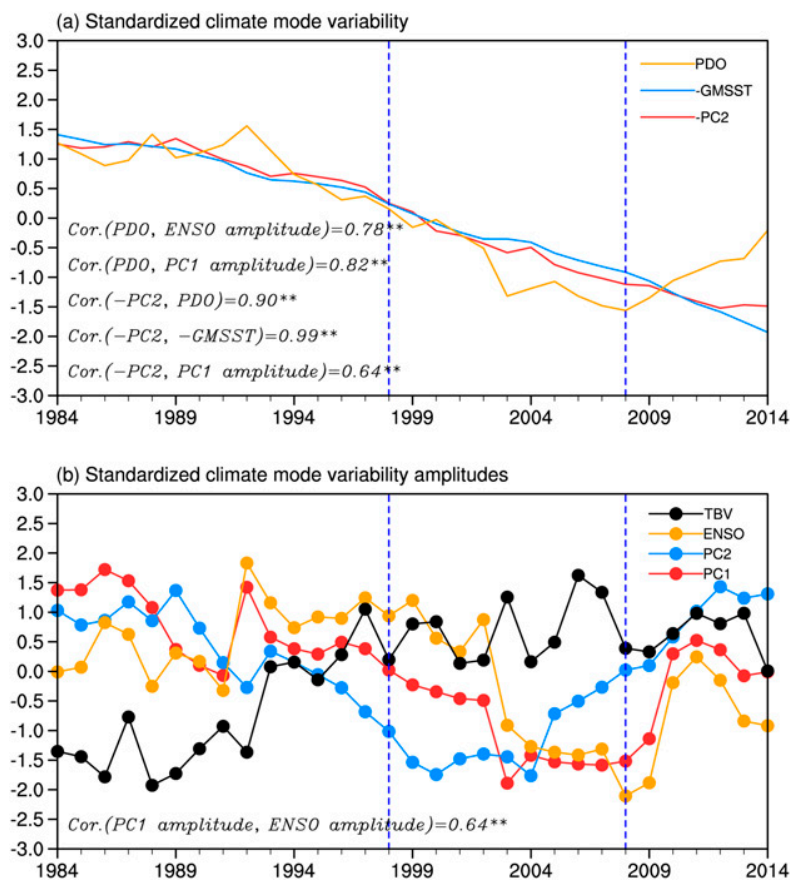

FIG. 12. (a) Standardized time series of the extended summer (May-October)-averaged Pacific decadal oscillation (PDO), negative global mean sea surface temperature (-GMSST), and negative PC2 of the second tropical sea surface temperature (SST) EOF mode on interdecadal time scales (using an 11-yr running mean). (b) As in (a), but for normalized PC1 amplitude, ENSO amplitude and TBV amplitude. The blue dashed lines denote the boundary between $\mathrm{P} 1, \mathrm{P} 2$, and $\mathrm{P} 3$.

environmental factors for TC genesis changes over the CENP and NATL basins (Table 3). When the amplitude of the ENSO-like mode (PC1) is relatively strong during P1 and P3, a significant modulation of the ENSO-like mode (PC1) on TCs over these two basins is observed. In contrast, there is a weak correlation between the ENSO-like mode (PC1) and TCF over these two basins during P2 when the amplitude of the ENSOlike mode $(\mathrm{PC} 1)$ is relatively weak. Considering that there is a significant correlation between PC1 amplitude and Niño-3.4 amplitude ( $r=0.64$ ) (Fig. 12b), this phenomenon can likely be explained by the strong relationship between the PDO and ENSO amplitude on interdecadal time scales $(r=0.78)$ (Imada and Kimoto 2009; Choi et al. 2013). Given the significant correlation between the PDO and the ENSO-like mode (PC1) amplitude $(r=0.82)$ (Fig. 12a), the decadal change in PC1 amplitude may be attributed to the PDO phase change, as reported by previous studies on the significant modulation of ENSO by the PDO (Zhao and Wang 2016, 2019).

We find that the TBV-like mode (PC2) appears to be the primary factor contributing to decadal changes in the TBVTCF relationship over the WNP basin. Although the TBV-like pattern (PC2) modulates TCF over the WNP basin (Table 3), its associated lower-tropospheric vorticity is relatively weak $(r=-0.57)$ and displays no significant impact on TCs. Together with interdecadal changes in the amplitude of the 
ENSO-like mode (PC1) (Fig. 12b), we hypothesize that decadal changes in the amplitude of the ENSO-like mode (PC1) relative to the amplitude of the $\mathrm{TBV}$-like mode $(\mathrm{PC} 2)$ is one of the main reasons for decadal changes in the TBV-TCF relationship over the WNP basin. The ENSO-like mode (PC1) dominates TBV during P1 and P3 when the amplitude of the ENSO-like mode (PC1) amplitude is substantially stronger relative to the TBV-like mode (Fig. 9c), leading to a typical southeast-northwest dipolar TC pattern as discussed in previous studies (Lander 1994; Wang and Chan 2002; Camargo and Sobel 2005). Consequently, we find no significant correlation between TBV and TCF during P1 and P3. In contrast, during P2, the amplitudes of the TBV-like (PC2) and the ENSO-like mode (PC1) are relatively equal (Fig. 9c), amplifying the basinwide impact of the TBV-like mode over the WNP, leading to a significant correlation between the TBV and TCF. Additionally, we note that a larger correlation between the TBV-like mode (PC2) and TCF over the WNP basin (Table 3), suggesting a possible modulation of ENSO-like mode (PC1) amplitude variability by interdecadal changes in the TBV-like mode (PC2). We hypothesize that the combination of the ENSO-like (PC1) and the TBV-like modes (PC2) are modulated by decadal variability in the ENSO-like mode (PC1) as well as interdecadal variations in the phase of the PDO. Furthermore, decadal changes in the interannual TBVTCF relationship seem to have a better consistency with TBV amplitude (Fig. 12b), especially during P2 compared with the linearly reconstructed TBV index using PC1 and PC2. The nonlinear interaction between the ENSO-like mode (PC1) and TBV-like mode (PC2) may partly explains this phenomenon.

One issue we note is that the PDO is consistent with the TBV-like mode (PC2) during P1 and P2 but has an opposite relationship during $\mathrm{P}$ 3. Global mean sea surface temperature shows a consistent relationship with the TBV-like mode (PC2) during the whole period (Fig. 12a). The impact of TBV on TCs over the CENP and NATL basin during P3 is potentially affected by global warming. Given the possible impact of global warming on the second EOF mode (e.g., the TBV-like mode), we conducted the same analyses with detrended tropical SSTAs. We found virtually identical EOF modes as in Fig. 9, and also found a similar strong consistency between the TBVlike mode (PC2) and the PDO (figure not shown).We further calculate the correlation between PC1 amplitude and PC2 on interdecadal time scales and find a significant negative relationship ( $r=-0.64)$ (Fig. 12a), suggesting a large modulation of the TBV-like mode by ENSO-like mode variability. Generally, these results indicate that the TBV-like mode (PC2) is possibly forced by the PDO, and the TBV-like mode (PC2) may modulate ENSO amplitude via the PDO.

\section{Summary}

In this study, we investigated decadal changes in the relationship between TBV and TCF over the WNP, CENP, and NATL basins. We find three distinct subperiods (P1: 1979-97; P2: 1998-2008; P3: 2009-19) impacting the interannual relationship between TBV and total TCF over the three basins (Fig. 2). During P1 and P3, we find a significant interannual correlation between TBV and TCF over the CENP and NATL basins, while TBV has a weak correlation with TCF during P2. The opposite interannual TBV-TCF relationship over the WNP basin is found to be opposite to those over the CENP and NATL basins (Table 1). Correlations between TBV and TCF over the three basins show a consistent basinwide (dipole) pattern when there is a significant (insignificant) correlation between TBV and TCF over a specific basin (Fig. 3). These results are consistent with the correlation pattern between large-scale factors over the three basins and TBV (Figs. 5-7). We further find that TBV-related lower-tropospheric vorticity is one of the most important factors in modulating TCF over the WNP and NATL basins, based on the coherence of the correlation maps between TBV-TCF and lower-tropospheric vorticity-TCF. VWS associated with TBV appears to be the most important factor affecting TCF over the CENP basin, with a consistent basinwide correlation when there is a strong TBV-TCF association and a dipole correlation when there is a weak correlation between TBV and TCF.

The different modulation of TBV and ENSO on TC counts may be due to distinct differences of SST pattern associated with TBV and ENSO modes (Fig. 11). Interannual variability is dominant in ENSO for P1 and P3 whereas interdecadal variability contributes to the role of TBV for P2 (Figs. 8 and 9). To distinguish TBV and ENSO, an EOF analysis is conducted on tropical SST with the first two dominant modes representing ENSO and TBV (Fig. 9). An ENSO-like pattern (PC1) with stronger interannual variability is dominant during P1 and P3 and has a smaller amplitude during $\mathrm{P} 2$. Correspondingly, weak decadal variability is observed during $\mathrm{P} 1$ and $\mathrm{P} 3$, while stronger decadal variability is found during P2. As a result, large-scale environmental factors (e.g., lower-tropospheric vorticity and VWS) associated with the ENSO-like pattern (PC1) leads to consistent basinwide TCF over the CENP and NATL basin as well as a dipolar TCF pattern over the WNP during P1 and P3 (Table 3). Lower-tropospheric vorticity modulations linked with TBV-like (PC2) $(r=-0.57)$ and ENSO-like modes (PC1) $(r=-0.47)$ are likely the most important factor causing basinwide TCF changes over the WNP during P2 (Table 3). Decadal changes in the interannual TBV-TCF relationship over the CENP and NATL basins may be explained by interdecadal variability of the TBV-like mode (PC2) and the ENSO-like mode (PC1). This process is demonstrated via modulation by the PDO of ENSO amplitude (Fig. 12). Over the WNP basin, the decadal changes in the TBV-TCF relationship appear to be closely associated with the TBV-like mode (PC2). Note that the TCF over the WNP basin has better consistency with TBV amplitude relative to the linearly reconstructed TBV index, highlighting that the nonlinear interaction between the ENSO-like (PC1) and TBV-like (PC2) modes plays a substantial role.

Last, note that the links between decadal changes of the impact of TBV on TCF over the three basins are largely based upon correlation analysis in this study, and caution should be taken since sample size limits these analyses. More observational studies and numerical simulations to further understand the physical mechanisms of how the TBV impacts TCs are warranted. 
Acknowledgments. This research was jointly supported by the National Natural Science Foundation of China (Grants 41922033, 41675072, and 41730961), the Natural Science Foundation of Jiangsu Province (Grant BK20181412), the project of the "Six Talent Peaks Project" in Jiangsu Province (2019-JY-100), the Postgraduate Research and Practice Innovation Program of Jiangsu Province (KYCX21_0948), and the Open Grants of the State Key Laboratory of Severe Weather (2021LASW-B08). P. Klotzbach would like to acknowledge a grant from the G. Unger Vetlesen Foundation.

\section{REFERENCES}

Bister, M., and K. A. Emanuel, 2002: Low frequency variability of tropical cyclone potential intensity 1 . Interannual to interdecadal variability. J. Geophys. Res., 107, 4801, https://doi.org/ 10.1029/2001JD000776.

Cai, W., and Coauthors, 2019: Pantropical climate interactions. Science, 363, eaav4236, https://doi.org/10.1126/science.aav4236.

Camargo, S. J., and A. H. Sobel, 2005: Western North Pacific tropical cyclone intensity and ENSO. J. Climate, 18, 29963006, https://doi.org/10.1175/JCLI3457.1.

_ , K. A. Emanuel, and A. H. Sobel, 2007: Use of a genesis potential index to diagnose ENSO effects on tropical cyclone genesis. J. Climate, 20, 4819-4834, https://doi.org/10.1175/ JCLI4282.1.

Cao, X., S. Chen, G. Chen, and R. Wu, 2016: Intensified impact of northern tropical Atlantic SST on tropical cyclogenesis frequency over the western North Pacific after the late 1980s. Adv. Atmos. Sci., 33, 919-930, https://doi.org/10.1007/s00376016-5206-z.

- - , R. Wu, and X. Xiao, 2018: A new perspective of intensified impact of ENSO Modoki on tropical cyclone genesis frequency over the western North Pacific around 1990. Int. J. Climatol., 38, 4264-4275, https://doi.org/ $10.1002 /$ joc. 5667.

Caron, L. P., M. Boudreault, and S. J. Camargo, 2015: On the variability and predictability of eastern Pacific tropical cyclone activity. J. Climate, 28, 9678-9696, https://doi.org/10.1175/ JCLI-D-15-0377.1.

Chan, J. C. L., 1985: Tropical cyclone activity in the northwest Pacific in relation to the El Niño/Southern Oscillation phenomenon. Mon. Wea. Rev., 113, 599-606, https://doi.org/ 10.1175/1520-0493(1985)113<0599:TCAITN >2.0.CO;2.

Chang, T. C., H. H. Hsu, and C. C. Hong, 2016: Enhanced influences of tropical Atlantic SST on WNP-NIO atmosphereocean coupling since the early 1980s. J. Climate, 29, 6509-6525, https://doi.org/10.1175/JCLI-D-15-0807.1.

Chikamoto, Y., and Coauthors, 2015: Skillful multi-year predictions of tropical trans-basin climate variability. Nat. Commun., 6, 6869, https://doi.org/10.1038/ncomms7869.

Choi, J., S. I. An, S. W. Yeh, and J. Y. Yu, 2013: ENSO-like and ENSO-induced tropical Pacific decadal variability in CGCMs. J. Climate, 26, 1485-1501, https://doi.org/10.1175/JCLI-D-1200118.1.

Choudhury, D., A. S. Gupta, A. Sharma, A. S. Taschetto, R. Mehrotra, and B. Sivakumar, 2017: Impacts of the tropical trans-basin variability on Australian rainfall. Climate Dyn., 49, 1617-1629, https://doi.org/10.1007/s00382-016-3405-z.

Chu, J.-H., C. R. Sampson, A. S. Levine, and E. Fukada, 2002: The Joint Typhoon Warning Center tropical cyclone best-tracks, 1945-2000. Naval Research Laboratory Rep. NRL/MR/754002-16, $22 \mathrm{pp}$.
Collins, J. M., 2007: The relationship of ENSO and relative humidity to interannual variations of hurricane frequency in the North-East Pacific Ocean. Papers Appl. Geogr. Conf., 30, 324333, https://scholarcommons.usf.edu/geo_facpub/168.

Craig, G. C., and S. L. Gray, 1996: CISK or WISHE as the mechanism for tropical cyclone intensification. J. Atmos. Sci., 53, 3528-3540, https://doi.org/10.1175/1520-0469(1996)053<3528: COWATM $>2.0 . \mathrm{CO} ; 2$.

DeMaria, M., 1996: The effect of vertical shear on tropical cyclone intensity change. J. Atmos. Sci., 53, 2076-2088, https://doi.org/ 10.1175/1520-0469(1996)053<2076:TEOVSO > 2.0.CO;2.

Du, Y., L. Yang, and S.-P. Xie, 2011: Tropical Indian Ocean influence on northwest Pacific tropical cyclones in summer following strong El Niño. J. Climate, 24, 315-322, https://doi.org/ 10.1175/2010JCLI3890.1.

Emanuel, K., 2013: Downscaling CMIP5 climate models shows increased tropical cyclone activity over the 21st century. Proc. Natl. Acad. Sci. USA, 110, 12219-12224, https://doi.org/ 10.1073/pnas.1301293110.

- , and D. S. Nolan, 2004: Tropical cyclone activity and the global climate system. 26th Conf. on Hurricanes and Tropical Meteorology, Miami, FL, Amer. Meteor. Soc., 240-241.

Fisher, R. A., 1915: Frequency distribution of the values of the correlation coefficient in samples of an indefinitely large population. Biometrika, 10, 507-521, https://doi.org/10.2307/2331838.

Frank, W. M., and E. A. Ritchie, 2001: Effects of vertical wind shear on the intensity and structure of numerically simulated hurricanes. Mon. Wea. Rev., 129, 2249-2269, https://doi.org/ 10.1175/1520-0493(2001)129<2249:EOVWSO > 2.0.CO;2.

Gao, S., Z. Chen, and W. Zhang, 2018: Impacts of tropical North Atlantic SST on western North Pacific landfalling tropical cyclones. J. Climate, 31, 853-862, https://doi.org/10.1175/JCLID-17-0325.1.

Goldenberg, S. B., and L. J. Shapiro, 1996: Physical mechanisms for the association of El Niño and West African rainfall with Atlantic major hurricane activity. J. Climate, 9, 1169-1187, https://doi.org/ 10.1175/1520-0442(1996)009<1169:PMFTAO>2.0.CO;2.

Grassi, B., G. Redaelli, P. O. Canziani, and G. Visconti, 2012: Effects of the PDO phase on the tropical belt width. J. Climate, 25, 3282-3290, https://doi.org/10.1175/JCLI-D-11-00244.1.

Gray, W. M., 1975: Tropical cyclone genesis. Atmospheric Science Paper 234, Colorado State University, 121 pp.

_ 1979: Hurricanes: Their formation, structure and likely role in the tropical circulation. Meteorology over the Tropical Oceans, D. B. Shaw, Eds., Royal Meteorological Society, 155218.

_ 1984: Atlantic seasonal hurricane frequency. Part I: El Niño and $30 \mathrm{mb}$ quasi-biennial oscillation influences. Mon. Wea. Rev., 112, 1649-1668, https://doi.org/10.1175/1520-0493(1984) 112<1649:ASHFPI >2.0.CO;2.

Ha, Y., Z. Zhong, X. Yang, and Y. Sun, 2015: Contribution of East Indian Ocean SSTA to western North Pacific tropical cyclone activity under El Niño/La Niña conditions. Int. J. Climatol., 35, 506-519, https://doi.org/10.1002/joc.3997.

Haarsma, R. J., J. F. Mitchell, and C. A. Senior, 1993: Tropical disturbances in a GCM. Climate Dyn., 8, 247-257, https:// doi.org/10.1007/BF00198619.

Held, I. M., and M. Zhao, 2011: The response of tropical cyclone statistics to an increase in $\mathrm{CO}_{2}$ with fixed sea surface temperatures. J. Climate, 24, 5353-5364, https://doi.org/10.1175/ JCLI-D-11-00050.1.

Ho, C. H., H. S. Kim, J. H. Jeong, and S. W. Son, 2009: Influence of stratospheric quasi-biennial oscillation on tropical cyclone 
tracks in the western North Pacific. Geophys. Res. Lett., 36, L06702, https://doi.org/10.1029/2009GL037163.

Hong, C. C., Y. H. Li, T. Li, and M. Y. Lee, 2011: Impacts of central Pacific and eastern Pacific El Niños on tropical cyclone tracks over the western North Pacific. Geophys. Res. Lett., 38, L16712, https://doi.org/10.1029/2011GL048821.

$\mathrm{Hu}, \mathrm{C}$., C. Zhang, S. Yang, D. Chen, and S. He, 2018: Perspective on the northwestward shift of autumn tropical cyclogenesis locations over the western North Pacific from shifting ENSO. Climate Dyn., 51, 2455-2465, https://doi.org/10.1007/s00382-017-4022-1.

Huang, B., and Coauthors, 2015: Extended reconstructed sea surface temperature version 4 (ERSST.v4). Part I: Upgrades and intercomparisons. J. Climate, 28, 911-930, https://doi.org/ 10.1175/JCLI-D-14-00006.1.

Huo, L., P. Guo, S. N. Hameed, and D. Jin, 2015: The role of tropical Atlantic SST anomalies in modulating western North Pacific tropical cyclone genesis. Geophys. Res. Lett., 42, 23782384, https://doi.org/10.1002/2015GL063184.

Iizuka, S., and T. Matsuura, 2009: Relationship between ENSO and North Atlantic tropical cyclone frequency simulated in a coupled general circulation model. Hurricanes and Climate Change, J. B. Elsner and T. H. Jagger, Eds., Springer, 323-338.

Imada, Y., and M. Kimoto, 2009: ENSO amplitude modulation related to Pacific decadal variability. Geophys. Res. Lett., 36, L03706, https://doi.org/10.1029/2008GL036421.

Jien, J. Y., W. A. Gough, and K. Butler, 2015: The influence of El Niño-Southern Oscillation on tropical cyclone activity in the eastern North Pacific basin. J. Climate, 28, 2459-2474, https://doi.org/10.1175/JCLI-D-14-00248.1.

Kanamitsu, M., W. Ebisuzaki, J. Woollen, S. Yang, J. J. Hnilo, M. Fiorino, and G. L. Potter, 2002: NCEP-DOE AMIP-II Reanalysis (R-2). Bull. Amer. Meteor. Soc., 83, 1631-1644, https://doi.org/10.1175/BAMS-83-11-1631.

Kao, H. Y., and J. Y. Yu, 2009: Contrasting eastern-Pacific and central-Pacific types of ENSO. J. Climate, 22, 615-632, https:// doi.org/10.1175/2008JCLI2309.1.

Kawamura, R., 1994: A rotated EOF analysis of global sea surface temperature variability with interannual and interdecadal scales. J. Phys. Oceanogr., 24, 707-715, https://doi.org/10.1175/ 1520-0485(1994)024<0707:AREAOG > 2.0.CO;2.

Klotzbach, P. J., 2011: El Niño-Southern Oscillation's impact on Atlantic basin hurricanes and U.S. landfalls. J. Climate, 24, 1252-1263, https://doi.org/10.1175/2010JCLI3799.1.

- , and E. S. Blake, 2013: North-central Pacific tropical cyclones: Impacts of El Niño-Southern Oscillation and the MaddenJulian oscillation. J. Climate, 26, 7720-7733, https://doi.org/ 10.1175/JCLI-D-12-00809.1.

—, S. G. Bowen, R. Pielke Jr., and M. M. Bell, 2018: Continental United States landfall frequency and associated damage: Observations and future risks. Bull. Amer. Meteor. Soc., 99, 1359-1376, https://doi.org/10.1175/BAMS-D-17-0184.1.

Knaff, J. A., S. A. Seseske, M. DeMaria, and J. L. Demuth, 2004: On the influences of vertical wind shear on symmetric tropical cyclone structure derived from AMSU. Mon. Wea. Rev., 132, 2503-2510, https://doi.org/10.1175/1520-0493(2004)132<2503: OTIOVW $>2.0 . \mathrm{CO} ; 2$.

Knapp, K. R., M. C. Kruk, D. H. Levinson, H. J. Diamond, and C. J. Neumann, 2010: The International Best Track Archive for Climate Stewardship (IBTrACS) unifying tropical cyclone data. Bull. Amer. Meteor. Soc., 91, 363-376, https://doi.org/ 10.1175/2009BAMS2755.1.

Knutson, T. R., and Coauthors, 2010: Tropical cyclones and climate change. Nat. Geosci., 3, 157-163, https://doi.org/10.1038/ngeo779.
Lander, M. A., 1994: An exploratory analysis of the relationship between tropical storm formation in the western North Pacific and ENSO. Mon. Wea. Rev., 122, 636-651, https://doi.org/ 10.1175/1520-0493(1994)122<0636:AEAOTR > 2.0.CO;2.

Landsea, C. W., and J. L. Franklin, 2013: Atlantic hurricane database uncertainty and presentation of a new database format. Mon. Wea. Rev., 141, 3576-3592, https://doi.org/10.1175/MWR-D-1200254.1.

Liu, K. S., and J. C. Chan, 2008: Interdecadal variability of western North Pacific tropical cyclone tracks. J. Climate, 21, 44644476, https://doi.org/10.1175/2008JCLI2207.1.

Liu, W., and Coauthors, 2015: Extended reconstructed sea surface temperature version 4 (ERSST.v4): Part II. Parametric and structural uncertainty estimations. J. Climate, 28, 931-951, https://doi.org/10.1175/JCLI-D-14-00007.1.

Liu, Y., P. Huang, and G.-H. Chen, 2019: Impacts of the combined modes of the tropical Indo-Pacific sea surface temperature anomalies on the tropical cyclone genesis over the western North Pacific. Int. J. Climatol., 39, 2108-2119, https://doi.org/ 10.1002/joc.5938.

Luo, J. J., G. Liu, H. Hendon, O. Alves, and T. Yamagata, 2017: Inter-basin sources for two-year predictability of the multiyear La Niña event in 2010-2012. Sci. Rep., 7, 2276, https:// doi.org/10.1038/s41598-017-01479-9.

McBride, J. L., 1981: Observational analysis of tropical cyclone formation. Part I: Basic description of data sets. J. Atmos. Sci., 38, 1117-1131, https://doi.org/10.1175/1520-0469(1981)038<1117: OAOTCF $>2.0 . \mathrm{CO} ; 2$.

McGregor, S., A. Timmermann, M. F. Stuecker, M. H. England, M. Merrifield, F. F. Jin, and Y. Chikamoto, 2014: Recent Walker circulation strengthening and Pacific cooling amplified by Atlantic warming. Nat. Climate Change, 4, 888-892, https:// doi.org/10.1038/nclimate2330.

— M. F. Stuecker, J. B. Kajtar, M. H. England, and M. Collins, 2018: Model tropical Atlantic biases underpin diminished Pacific decadal variability. Nat. Climate Change, 8, 493-498, https://doi.org/10.1038/s41558-018-0163-4.

Montgomery, M. T., and Coauthors, 2012: The Pre-Depression Investigation of Cloud-Systems in the Tropics (PREDICT) experiment: Scientific basis, new analysis tools, and some first results. Bull. Amer. Meteor. Soc., 93, 153-172, https://doi.org/ 10.1175/BAMS-D-11-00046.1.

Murakami, H., B. Wang, and A. Kitoh, 2011: Future change of western North Pacific typhoons: Projections by a $20-\mathrm{km}-\mathrm{mesh}$ global atmospheric model. J. Climate, 24, 1154-1169, https:// doi.org/10.1175/2010JCLI3723.1.

Nguyen, H., A. Evans, C. Lucas, I. Smith, and B. Timbal, 2013: The Hadley circulation in reanalyses: Climatology, variability, and change. J. Climate, 26, 3357-3376, https://doi.org/10.1175/ JCLI-D-12-00224.1.

Oouchi, K., J. Yoshimura, H. Yoshimura, R. Mizuta, S. Kusunoki, and A. Noda, 2006: Tropical cyclone climatology in a global-warming climate as simulated in a $20 \mathrm{~km}$-mesh global atmospheric model: Frequency and wind intensity analyses. J. Meteor. Soc. Japan, 84, 259-276, https://doi.org/10.2151/jmsj.84.259.

Park, J. H., S. I. An, and J. S. Kug, 2017: Interannual variability of western North Pacific SST anomalies and its impact on North Pacific and North America. Climate Dyn., 49, 3787-3798, https://doi.org/10.1007/s00382-017-3538-8.

Patricola, C. M., S. J. Camargo, P. J. Klotzbach, R. Saravanan, and P. Chang, 2018: The influence of ENSO flavors on western North Pacific tropical cyclone activity. J. Climate, 31, 53955416, https://doi.org/10.1175/JCLI-D-17-0678.1. 
Rasmusson, E. M., and T. H. Carpenter, 1982: Variations in tropical sea surface temperature and surface wind fields associated with the Southern Oscillation/El Niño. Mon. Wea. Rev., 110, 354-384, https://doi.org/10.1175/1520-0493(1982) $110<0354$ :VITSST $>2.0$.CO;2.

Rogers, R., and Coauthors, 2006: The intensity forecasting experiment: A NOAA multiyear field program for improving tropical cyclone intensity forecasts. Bull. Amer. Meteor. Soc., 87, 1523-1538, https://doi.org/10.1175/BAMS-87-11-1523.

Royer, J. F., F. Chauvin, B. Timbal, P. Araspin, and D. Grimal, 1998: A GCM study of the impact of greenhouse gas increase on the frequency of occurrence of tropical cyclones. Climatic Change, 38, 307-343, https://doi.org/10.1023/A:1005386312622.

Schreck, C. J., K. R. Knapp, and J. P. Kossin, 2014: The impact of best track discrepancies on global tropical cyclone climatologies using IBTrACS. Mon. Wea. Rev., 142, 3881-3899, https:// doi.org/10.1175/MWR-D-14-00021.1.

Sharmila, S., and K. J. E. Walsh, 2018: Recent poleward shift of tropical cyclone formation linked to Hadley cell expansion. Nat. Climate Change, 8, 730-736, https://doi.org/10.1038/s41558-0180227-5.

Sobel, A. H., and E. D. Maloney, 2000: Effect of ENSO and the MJO on western North Pacific tropical cyclones. Geophys. Res. Lett., 27, 1739-1742, https://doi.org/10.1029/1999GL011043.

Song, J., and P. J. Klotzbach, 2018: What has controlled the poleward migration of annual averaged location of tropical cyclone lifetime maximum intensity over the western North Pacific since 1961? Geophys. Res. Lett., 45, 1148-1156, https:// doi.org/10.1002/2017GL076883.

Sugi, M., H. Murakami, and J. Yoshimura, 2009: A reduction in global tropical cyclone frequency due to global warming. SOLA, 5, 164167, https://doi.org/10.2151/sola.2009-042.

,-- , and 2012: On the mechanism of tropical cyclone frequency changes due to global warming. J. Meteor. Soc. Japan, 90A, 397-408, https://doi.org/10.2151/jmsj.2012-A24.

Sullivan, A., J.-J. Luo, A. C. Hirst, D. Bi, W. Cai, and J. He, 2016: Robust contribution of decadal anomalies to the frequency of central-Pacific El Niño. Sci. Rep., 6, 38540, https://doi.org/ 10.1038/srep38540.

Wang, B., and J. C. Chan, 2002: How strong ENSO events affect tropical storm activity over the western North Pacific. J. Climate, 15, 1643-1658, https://doi.org/10.1175/1520-0442(2002) 015<1643:HSEEAT $>2.0$. CO;2.

Wang, C., and S.-K. Lee, 2009: Co-variability of tropical cyclones in the North Atlantic and the eastern North Pacific. Geophys. Res. Lett., 36, L24702, https://doi.org/10.1029/2009GL041469.

Wang, X., and H. Liu, 2016: PDO modulation of ENSO effect on tropical cyclone rapid intensification in the western North Pacific. Climate Dyn., 46, 15-28, https://doi.org/10.1007/s00382015-2563-8.

Wu, L., and B. Wang, 2004: Assessing impacts of global warming on tropical cyclone tracks. J. Climate, 17, 1686-1698, https:// doi.org/10.1175/1520-0442(2004)017<1686: AIOGWO $>2.0 . \mathrm{CO} ; 2$.

Wu, R., X. Cao, and Y.-Y. Yang, 2020: Interdecadal change in the relationship of the western North Pacific tropical cyclogenesis frequency to tropical Indian and North Atlantic Ocean SST in early 1990s. J. Geophys. Res. Atmos., 125, e2019JD031493, https://doi.org/10.1029/2019JD031493.

Xiang, B., B. Wang, and T. Li, 2013: A new paradigm for the predominance of standing central Pacific warming after the late 1990s. Climate Dyn., 41, 327-340, https://doi.org/10.1007/ s00382-012-1427-8.

Xie, S.-P., K. Hu, J. Hafner, H. Tokinaga, Y. Du, G. Huang, and T. Sampe, 2009: Indian Ocean capacitor effect on Indo-western Pacific climate during the summer following El Niño. J. Climate, 22, 730-747, https://doi.org/10.1175/2008JCLI2544.1.

Yang, J. C., X. Lin, and S. P. Xie, 2017: A trans-basin mode of interannual variability of the Central American gap winds: Seasonality and large-scale forcing. J. Climate, 30, 8223-8235, https://doi.org/10.1175/JCLI-D-17-0021.1.

Yoon, J., and S. W. Yeh, 2010: Influence of the Pacific decadal oscillation on the relationship between El Niño and the northeast Asian summer monsoon. J. Climate, 23, 4525-4537, https://doi.org/10.1175/2010JCLI3352.1.

Yoshimura, J., M. Sugi, and A. Noda, 2006: Influence of greenhouse warming on tropical cyclone frequency. J. Meteor. Soc. Japan, 84, 405-428, https://doi.org/10.2151/jmsj.84.405.

Yu, J., T. Li, Z. Tan, and Z. Zhu, 2016: Effects of tropical North Atlantic SST on tropical cyclone genesis in the western North Pacific. Climate Dyn., 46, 865-877, https://doi.org/10.1007/ s00382-015-2618-X.

Zhan, R., Y. Wang, and X. Lei, 2011: Contributions of ENSO and east Indian Ocean SSTA to the interannual variability of northwest Pacific tropical cyclone frequency. J. Climate, 24, 509-521, https://doi.org/10.1175/2010JCLI3808.1.

$\longrightarrow, \ldots$, and L. Tao, 2014: Intensified impact of East Indian Ocean SST anomaly on tropical cyclone genesis frequency over the western North Pacific. J. Climate, 27, 8724-8739, https://doi.org/10.1175/JCLI-D-14-00119.1.

Zhang, J. Y., L. G. Wu, and Q. Zhang, 2011: Tropical cyclone damages in China under the background of global warming. J. Trop. Meteor., 27, 442-454.

Zhang, Q., L. Wu, and Q. Liu, 2009: Tropical cyclone damages in China 1983-2006. Bull. Amer. Meteor. Soc., 90, 489-496, https:// doi.org/10.1175/2008BAMS2631.1.

Zhao, H., and L. Wu, 2014: Inter-decadal shift of the prevailing tropical cyclone tracks over the western North Pacific and its mechanism study. Meteor. Atmos. Phys., 125, 89-101, https:// doi.org/10.1007/s00703-014-0322-8.

- and C. Wang, 2016: Interdecadal modulation on the relationship between ENSO and typhoon activity during the late season in the western North Pacific. Climate Dyn., 47, 315-328, https://doi.org/10.1007/s00382-015-2837-1.

— tropical cyclones in the western North Pacific during the boreal summer. Climate Dyn., 52, 275-288, https://doi.org/ 10.1007/s00382-018-4136-0.

— L. Wu, and W. Zhou, 2010: Assessing the influence of the ENSO on tropical cyclone prevailing tracks in the western North Pacific. Adv. Atmos. Sci., 27, 1361-1371, https://doi.org/ 10.1007/s00376-010-9161-9.

_ S. Chen, and P. J. Klotzbach, 2019a: Recent strengthening of the relationship between the western North Pacific monsoon and western North Pacific tropical cyclone activity during the boreal summer. J. Climate, 32, 8283-8299, https://doi.org/ 10.1175/JCLI-D-19-0016.1.

, J. Zhang, P. J. Klotzbach, and S. Chen, 2019b: Recent increased co-variability of tropical cyclogenesis latitude-longitude over the western North Pacific during the extended boreal summer. J. Climate, 32, 8167-8179, https://doi.org/10.1175/JCLI-D19-0009.1. 